\title{
THE PROBOSCIS APPARATUS OF ARENICOLA
}

\author{
By G. P. Wells \\ Department of Zoology, University College, London
}

(Plates I-IV and Text-figs. I-I4)

\begin{abstract}
CONTENTS
Introduction .

General account of the proboscis apparatus

Serial homology of the proboscis apparatus

Modifications of the proboscis apparatus in Arenicola ecaudata Johnston, A. claparedii Levinsen and $A$. marina L.

The proboscis

The buccal peritoneum

The gular membrane

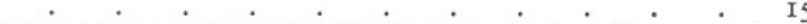

The union of retractor sheath and phe and retractor sheath on the body wall . $\quad$ I8

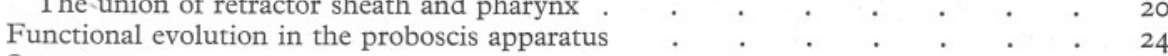

Summary .

References

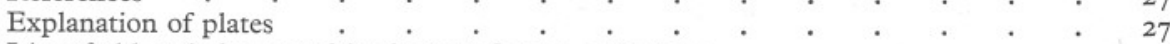

List of abbreviations used in the text-figures and plates $\cdot \cdot \cdot \cdot \cdot \cdot{ }^{\cdot} \cdot{ }^{\cdot}{ }^{\cdot}$
\end{abstract}

\section{INTRODUCTION}

The anterior end of Arenicola contains an elaborately organized apparatus which has hitherto escaped accurate description, although it is of evident importance in the processes of extrusion and withdrawal of the proboscis, and exhibits striking variations within the genus as at present constituted. The 'proboscis apparatus', as it will be termed, includes the following components: (i) the proboscis itself and the first part of the oesophagus, together constituting the anterior portion of the gut; and (ii) the retractor sheath and gular membrane ('first septum' or 'first diaphragm' of previous authors), both of which, in the writer's view, are derived from the first septum. Although of diverse morphological origin, these components are built together into a functionally unified whole. The purpose of the following paper is to give an account of the anatomy of the apparatus on which later studies of its mode of action can be based. The three species to be described, $A$. ecaudata Johnston, $A$. claparedii Levinsen and $A$. marina L., are chosen to represent the three sections into which the genus naturally falls. It will be shown that the proboscis apparatus undergoes characteristic structural modifications in each of the three, although its basal plan is always the same. So great are the divergences that probably each of them extrudes its proboscis in a different way. 
A revision of the external characters, body wall and parapodia of the same three species was recently published (Wells, I950). The material and anatomical methods described in that paper apply also to the present one, except that I have received some excellent additional material of $A$. claparedii from Departure Bay, Nanaimo, by the kindness of Dr Peter Ford, of the Department of Zoology, University of British Columbia.

The chief point of difficulty in studying the anatomy of the proboscis apparatus is the diversity of positions which it can assume. The proboscis may be wholly or partly extruded, or withdrawn. When withdrawn its arrangement, and that of the associated structures, can vary greatly according to the configuration of the anterior end as a whole. Most of the anatomical descriptions refer to worms killed in one or other of two attitudes, termed 'relaxed' and 'distended'. Details of the methods of killing are given in the earlier paper. A relaxed worm is in a tolerably normal attitude, with the proboscis partly or wholly withdrawn. A distended worm has been narcotized and its body cavity blown up with fixative at the moment of killing. Its proboscis is extruded and all the parts are stretched to an abnormal degree, but the result is useful for the elucidation of many of the finer anatomical details. Except where otherwise stated, the descriptions refer to relaxed worms.

\section{General Account of the Proboscis Apparatus}

The three species to be considered represent divergent specializations of a common pattern. An account will first be given of the general plan of the proboscis apparatus, and afterwards the modifications shown by the three species will be described. The general account applies to all of the species, except where otherwise stated.

The simplest way to see the plan of the proboscis apparatus is to bisect the anterior end horizontally with a razor blade and examine it with a dissecting microscope (Pl. II, fig. 3). Sagittal sections are often confusing because of certain elaborations which appear in the median plane. A generalized horizontal section, with the proboscis withdrawn, is shown in Text-fig. I, and described in the following paragraphs.

The 'head' of the worm is the bluntly conical region extending forwards from the anterior margin of the first chaetigerous annulus (Ch. I). Its body wall consists of the following layers: (i) epidermis (ep.); (ii) sub-epithelial connective tissue (c.t.); (iii) circular muscle (circ.m.); (iv) a layer of intermuscular connective tissue; (v) longitudinal muscle (long.m.); (vi) coelomic epithelium. The ventral nerve cord passes forward on to the head and divides into two connectives (conn.) which run upwards and forwards to the brain. The position of the nerve cord and connectives relative to the layers of the body wall varies from species to species. The connectives are accompanied by the metastomial muscles (metast.m.), which are derived from the longitudinal layer and pass obliquely upwards to meet each other immediately 
ventral to the brain. The structure of the body wall of the head was described in fuller detail elsewhere (Wells, I950).

The proboscis is the eversible part of the gut, and consists of: (i) a buccal mass, with large, prominent papillae whose form varies greatly from species to species (bucc.ma.); (ii) a pharynx, with finer, more closely set papillae

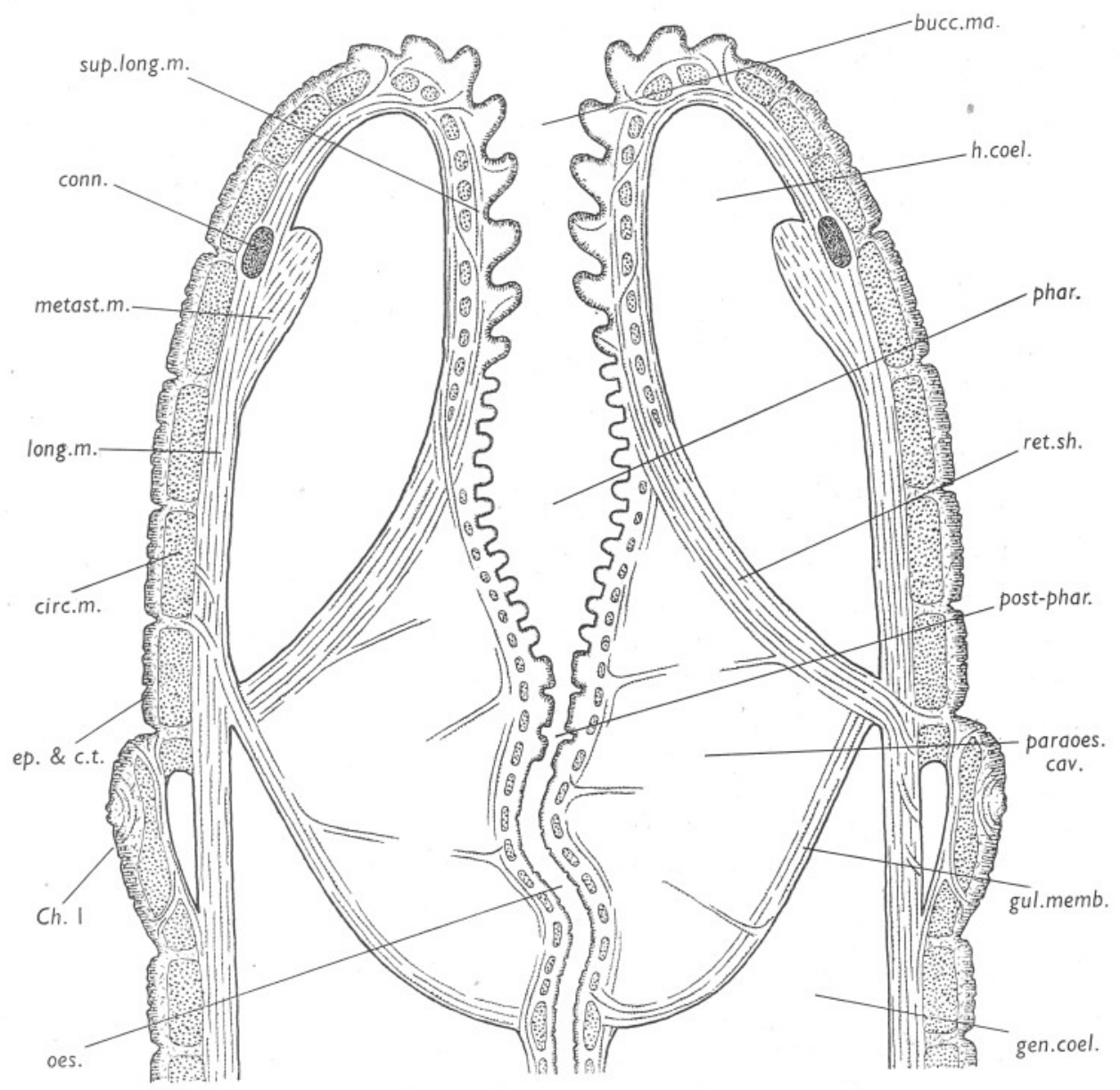

Text-fig. I. Generalized horizontal section through the anterior end of Arenicola. Lettering as on p. 28.

(phar.); (iii) a short post-pharynx with rather larger papillae (post-phar.). The post-pharynx is the extreme limit of that part of the gut which is turned inside-out during extrusion. It is followed by the more or less laterally compressed oesophagus (oes.).

The body wall continues into the proboscis at the mouth, and the walls of the proboscis and oesophagus are composed of layers having fundamentally 
the same arrangement as those of the body wall. There are, however, local specializations, of which the most striking is the presence in the buccal mass and the oral end of the pharynx of a superficial longitudinal muscle layer, lying between the circular muscle and the epithelium (sup.long.m.).

The individual proboscis papillae appear at first sight to be hollow outpushings of the gut wall. They are, however, more correctly described as thickenings of the wall which have become hollowed by the great development of the interstitial spaces between the cells (Pl. IV, figs. I, 2). They are bounded, on the surface towards the gut, by the epithelium and a thin layer of underlying connective tissue; they contain blood vessels and muscle fibres, the latter partly derived from the main muscle layers of the gut and partly intrinsic to the individual papillae. Because of these muscle fibres, and the extensive interstitial spaces, they have considerable powers of movement. Ideally, the spaces are cut off from the true coelom by the lining of the latter cavity, but the actual relationships vary from species to species, and from region to region of the proboscis.

The pharyngeal papillae vary somewhat in size, small ones being scattered about among their larger neighbours. This fact suggests that new papillae are intercalated all over the surface of the pharynx as the worm grows. The buccal papillae are of very uniform size, except that those at the oral and pharyngeal ends of the buccal mass are rather smaller than those in the middle. The growth of the buccal mass seems therefore to occur by increase in size of the individual papillae, and not by the intercalation of new ones among the old. The buccal mass and pharynx are separated by a more or less extensive transition zone bearing papillae of the pharyngeal type intermixed with others of the buccal type; the latter decrease in size from the buccal to the pharyngeal end of the transition zone and are finally no larger than the pharyngeal papillae, into which they merge (Pl. I, fig. I). The appearances could be due to a continual conversion of pharynx into buccal mass, taking place at the boundary between them.

The gut is suspended from the body wall of the head by two transverse sheets of tissue, the retractor sheath (ret.sh.) and the gular membrane (gul.memb.). The latter is the 'first diaphragm' or 'first septum' of Ashworth (I904, I9I2), but for reasons explained below I have substituted a name carrying no implication of serial homology.

The retractor sheath consists of coelomic epithelium, connective tissue and a single muscle layer in that order, the muscle layer lying on its hinder face. My sections-the thinnest of which are $15 \mu$, as they were made for fine anatomy rather than histology-also show a delicate endothelial layer on the hind face of the muscle in ecaudata, but not with any certainty in claparedii or marina. The muscle fibres run radially from the body wall to the gut, which they reach about half-way along the pharynx. Most of them then pass through the circular muscle layer of the gut to constitute the superficial 
longitudinal layer of the proboscis; the details of this region are, however, complicated and will be returned to in the detailed descriptions of the three species.

The gular membrane consists of the same layers as the retractor sheath, but in the reverse order-i.e. with the muscle layer in front of the connective tissue and epithelium. It varies greatly from species to species, both in general form and in the massiveness of its musculature. The latter runs radially in claparedii and marina, but is elaborated into a radial layer lying anterior to a circular one in ecaudata.

The retractor sheath and gular membrane are inserted together on the body wall, just in front of the first chaetigerous annulus. Their relations at this point can be imitated by tightly clasping one's hands and then extending the fingers. The palms of the hands represent the two sheets, and the fingers are the columns into which their radial muscle layers continue peripherally. The columns decussate and immediately enter the body wall. At first sight they appear to join the longitudinal layer, but serial sections show that a large part, at least, of their fibres make their way through to the connective tissue around and between the circular muscle bundles.

The horizontal section shows three large cavities between the gut and the body wall. These are the general coelome behind the gular membrane (gen.coel.), the head coelome in front of the retractor sheath (h.coel.), and the paraoesophageal cavity between the two sheets (paraoes.cav.). The paraoesophageal cavity contains a loose network of blood vessels lying freely within it, and is crossed by numerous very fine strands of muscle, the radial strands, which detach themselves from the retractor sheath and gular membrane and run to the wall of the gut.

The gular membrane and retractor sheath are imperforate, and therefore isolate the paraoesophageal cavity completely from the other cavities, except at certain special points as described below. The head coelome is separated from the general coelome by the peripheral muscle columns of the two sheets as they cross from their decussation to the body wall-the bases of the fingers, in the analogy of the clasped hands-but this barrier is never complete. Fluid can flow between head coelome and general coelome to an extent which varies, not only according to specific differences in form, but also according to the degree of contraction of the muscle columns.

On examining sagittal sections, or a sagittally dissected worm, certain additional points can be seen. A generalized sagittal section is shown in Text-fig. 2. The position of the central nervous system is given by the ventral nerve cord (n.c.), the brain (br.), and the dotted lines indicating the course of the connectives (conn.).

The position of the insertion of the retractor sheath and gular membrane on the body wall is shown as a fine ruled line. Ventrally and laterally, it is placed at or near the front border of the first chaetigerous annulus, but as the mid- 
dorsal line is approached it curves forwards to form, with its fellow of the opposite side, an anteriorly directed $\mathrm{V}$, the apex lying about half-way between the first chaetigerous annulus (Ch. I) and the nuchal groove (nuch.gr.). The line varies slightly in position from species to species.

The insertion of the retractor sheath and gular membrane is interrupted ventrally, in such a way as to leave a ventral foramen (vent.for.) through

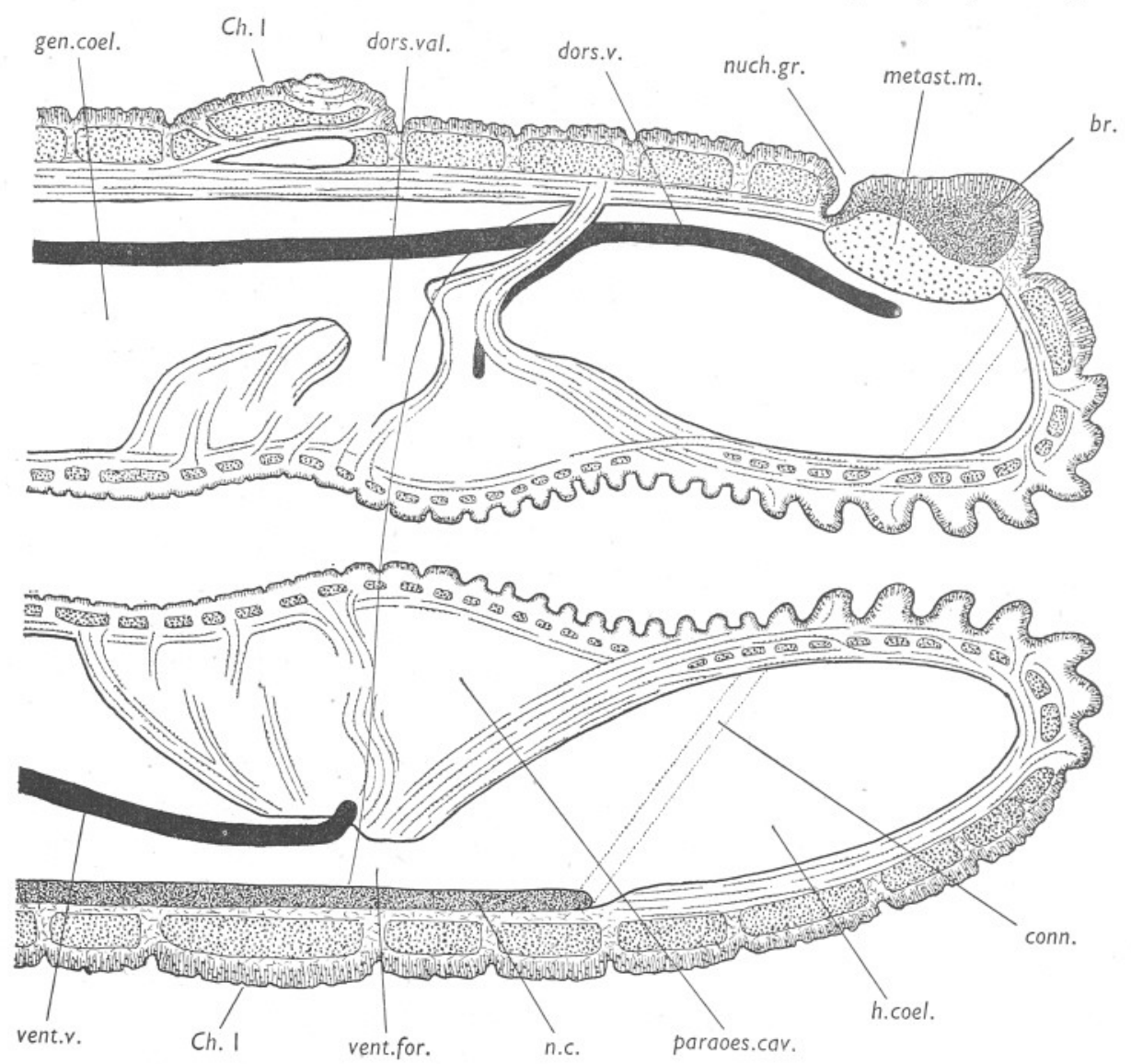

Text-fig. 2. Generalized median sagittal section through the anterior end of Arenicola. Lettering as on p. 28.

which the general coelome and head coelome communicate. This foramen is bounded laterally by the insertions of the two sheets, and could presumably be closed by contraction of their muscle columns. Its roof is the floor of the paraoesophageal cavity, which is thin and membranous in the mid-ventral line, the muscle columns having diverged to reach the body wall lateral to the foramen. 
The ventral vessel (vent.v.) ends anteriorly by passing upwards through the floor of the paraoesophageal cavity in the region of the ventral foramen, and breaking up into branches which join the vascular network lying in that cavity.

The radial muscle strands which cross the paraoesophageal cavity are especially well developed in the median plane. In particular, one or more thickened strands run from the lateral wall of the ventral foramen to the gut, which they reach just behind the post-pharynx. These strands may be regarded as a ventral accessory retractor of the proboscis.

Mid-dorsally, the gular membrane is thrown into a vertically descending fold, the dorsal valve (dors.val.). This fold is narrow from side to side, so that it has the general form, in horizontal section, of a flattened tube. The muscular layer of its lateral walls passes down as a series of strands to reach the gut just behind the post-pharynx; they probably act collectively as a dorsal accessory retractor of the proboscis. The membranous layer of the fold is continuous in its dorsal part but becomes perforated more ventrally, as it nears the gut. Body fluid can therefore make its way down the fold from the general coelome into the paraoesophageal cavity-a fact which explains the presence in the latter of coelomic corpuscles and developing germ cells identical with those found in the general coelome-but, owing to the lateral flattening of the tube, the passage of fluid in the reverse direction is presumably difficult.

The dorsal vessel (dors.v.) passes forwards through the insertion of the retractor sheath and gular membrane. As it does so, it gives off one or more branches which run downwards and backwards into the paraoesophageal cavity to join its vascular network.

\section{Serial Homology of the Proboscis Apparatus}

Ashworth's well known monograph of $A$. marina contains the following passage (Ashworth, I904, p. I9):

'The coelom is spacious and continuous from one end of the animal to the other. In front it is sub-divided transversely by three fenestrated septa, or diaphragms. The first of these is placed at the level of the anterior edge of the first chaetigerous annulus.... The second and third diaphragms mark the posterior limits of the second and third chaetigerous segments.'

The first of these diaphragms is our gular membrane. Ashworth evidently regarded all of the diaphragms as serially homologous with each other and as representing true septa (see also his pp. 22-4).

Ashworth's knowledge of the anatomical relationships inside the head was not very exact. In particular, he was unaware of the existence of the paraoesophageal cavity as a definitely walled-off space. He described the first diaphragm incorrectly as fenestrated, or 'perforated by numerous, rounded, 
usually oval apertures', as the third is, and he drew the retractor sheath, as it runs forwards from its decussation with the gular membrane, in the form of a series of separate slips instead of a continuous sheet (see his plate III, fig. 23). Moreover, he said nothing about the serial homology of the retractor sheath. As this structure meets the body wall just behind the gular membrane and the gut wall in front of the membrane, its derivation presents a difficult morphological problem if the gular membrane is in fact a septum.

Lillie (1905) published an account of the development of $A$. cristata Stimpson, a species which closely resembles $A$. marina. His main interest was in the nephridia, and he apparently relied for the rest of the adult anatomy on the works of Gamble \& Ashworth (I898, I900), on which Ashworth's monograph of 1904 is largely based. Lillie believed, contrary to Ashworth, that the first diaphragm has a different origin from the other two, and that none of them represent the primitive septa. His views on the second and third are irrelevant to the present discussion. With regard to the first diaphragm, or gular membrane, he wrote as follows (his p. 353):

\footnotetext{
'The most anterior septum occupies from the first a position immediately behind the line of insertion of the proboscideal retractor muscles (plate 24, fig. 35). As growth proceeds, the relations of these two originally independent structures become closer, and at the stage represented in fig. 36-in which twelve somites have been laid down - the two have become intimately associated with one another, though still distinguishable on close examination. This association of proboscideal muscles and first septum becomes in later stages more complete, and both eventually enter into the formation of the muscular first diaphragm. The posterior peritoneal wall of the adult diaphragm may be regarded as representing the original first septum.'
}

Lillie gave no information about the origin of the retractor sheath, whose first appearance in his account is as quoted above. Moreover, I have failed to find conclusive evidence for his interpretation in his published illustrations: this point is returned to below.

Ashworth afterwards accepted Lillie's views on the nature of the first diaphragm (Ashworth, I9I2, pp. 6I-2).

My own preference is for a third hypothesis, which may be stated as follows. The first chaetigerous segment was originally bounded anteriorly by a septum inserted on the body wall at the front border of the first chaetigerous annulus. This septum would consist of two layers of coelomic epithelium separated by connective tissue with muscle fibres and blood vessels in it. Let us assume that a cleft-the paraoesophageal cavity-has appeared in the middle layer of the septum, splitting it into two sheets. The anterior sheet becomes the retractor sheath, and the posterior sheet the gular membrane. If this be true, the paraoesophageal cavity is not coelomic.

This hypothesis has the advantage over its predecessors of finding a place for the retractor sheath in the segmental scheme. It explains why the sheath and the gular membrane are inserted at the same level on the body wall. The 
forward displacement of their plane of insertion in the mid-dorsal region supports the hypothesis, for a tendency to forward movement of the dorsal part of the septal insertions relative to the external annulation is visible in other segments of Arenicola. Moreover, the retractor sheath and gular membrane are so intimately related at certain points, notably in the median plane, that it is impossible to tell where one leaves off and the other begins. This might perhaps be due to the blending of two originally distinct structures, as Lillie suggested, but it is more simply explained if the sheath and membrane are in fact one structure.

The paraoesophageal cavity differs from the coelome in being crossed by the numerous radial muscle strands, and also in containing a network of vessels, lying freely in its cavity, to which both the dorsal and ventral vessels contribute. In other segments the dorsal and ventral vessels have no direct communication with each other except by means of commissural loops running in the septa, ${ }^{1}$ and if the paraoesophageal cavity represents a cleft within a septum, its vascular network can be derived from the commissural loop. The presence or absence of an epithelial lining to the cavity cannot be taken as evidence, for on the one hand, the coelomic epithelium can break down and disappear locally (e.g. in the buccal region of claparedii and marina), while on the other, many non-coelomic cavities, such as blood vessels, may acquire endothelial linings. The following point is, however, suggestive. My sections of claparedii show conspicuous brown 'chlorogogenous' cells on the ventral vessel. These cells, which are presumably derived from the coelomic epithelium, continue forwards exactly to the point of entry of the ventral vessel into the paraoesophageal cavity, where they end abruptly.

Although the hypothesis is in good agreement with the adult anatomy, it is rather in the early development that conclusive proof of its truth should be sought. Here I have no direct experience; but I have tried without success to find decisive evidence in Lillie's figures in favour either of his interpretation or of mine. The passage quoted above refers to his figs. 35 and 36 , which respectively show 8- and I2-somite larvae. Unfortunately, they are both sagittal sections and, because of the dorsal valve and the other complications which appear in the median plane, neither of them shows the relations of the retractor sheath and gular membrane at all clearly. If we turn to his figures of earlier stages, we find sections of 5- and 6-somite larvae in his figs. 7 and 8, plate 22. These are again sagittal, and their dorsal sides are difficult to understand, but their ventral sides are suggestive. In the 5-somite larva ('swarming stage') the mouth is still closed. The future proboscis appears to

1 These loops can be seen very clearly in the hinder branchiate segments of ecaudata, by isolating a single segment and examining in end view. The loops supply the gills and give off branches to the main longitudinal vessels of the body wall. The loops often persist even where the septa have disappeared, and are variously modified in the different regions of the body. That of the (vanished) septum vii forms the so-called ventricles. I hope to describe the loops in detail in a later work. 
be connected to the body wall by a thin membranous septum only. In the 6-somite larva ('beginning of crawling stage') the mouth is open and the proboscis has either just become, or is about to become, eversible (see his p. 347). The septum has now thickened into a broad wedge with its apex on the body wall and its base on the gut. This looks like the separation of a single septum into two sheets, rather than the merging of two originally distinct structures.

By the kindness of Dr Helen Pixell Goodrich, I have been allowed to use some horizontal sections of a I. 5 mm. A. cristata post-larva from Woods Hole, made by the late Prof. Goodrich. The tail is already nearly complete in this animal. A section of the anterior half, passing just ventral to the mouth, is shown in Pl. II, fig. 4. The metamerically arranged septa are clearly visible. If the convention is adopted that the septum at the anterior boundary of the $n$th chaetigerous segment is called the $n$th septum, then those marked $D$. II and $D$. III, which will become the 'second and third diaphragms' of the adult, are in reality the third and fourth septa. The second, marked D.vest., will become a vestigial diaphragm which can be clearly seen in the adult, connecting the corresponding segmental vessels to the body wall. One segment farther forwards, the future retractor sheath and gular membrane meet the body wall, and the suggestion seems irresistible that they both represent the first septum. Conclusive proof could perhaps be found in horizontal sections of earlier stages, with 5 or 6 somites. There is at least a possibility that the first septum would be seen in the act of division in such material.

\section{Modifications of the Proboscis Apparatus in ARENiCola ECAUDATA Johnston, $A$. CLAPAREDII Levinsen, AND A. MARINA L.}

The description of the proboscis apparatus in the three species follows a comparative plan, those parts of the apparatus which show important modifications being taken in order.

\section{The Proboscis}

The proboscis varies from species to species in general form and also in the form of the papillae.

The extruded proboscis of ecaudata generally has the form of a very flat cone, rather like a loudspeaker cone, with a slightly domed top-the cone being the buccal mass and the top the pharynx. The animals drawn in Textfigs. $3 E$. and $12 E$. were artificially distended after narcosis and show an extreme degree of inflation which is seldom or never attained in the living animal. The pharyngeal papillae are conical. Those of the buccal mass appear, when the proboscis is fully distended, as rounded or polygonal raised areas with flat tops. In the partly distended or withdrawn organ the centres of the tops sink down so that the buccal papillae are sucker-shaped (Text-fig. $4 E$.; 
Pl. I, fig. I; P1. II, fig. I). The arrangement of their musculature indicates that a sucker action is of real importance in their normal functioning, for there are strands running down from the tops to the deeper layers of the gut wall, which could cause depression, and others running across on the deep surfaces of the tops, which could cause raising and flattening (Pl. IV, fig. I). The contrast between the sucker-like buccal papillae of ecaudata and the tooth-like ones of the other two species is very great. The transition zone between buccal mass and pharynx, in which papillae of the two types are intermingled, is broad in ecaudata.

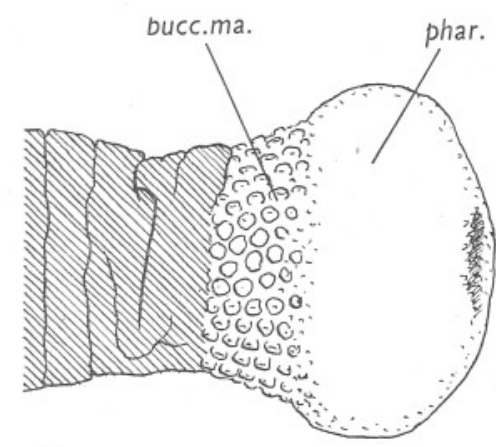

E.

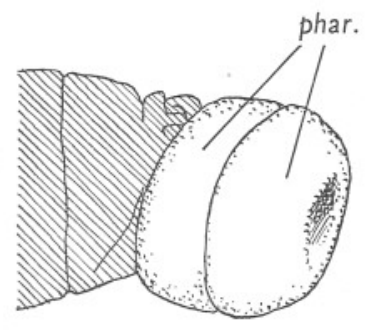

C.

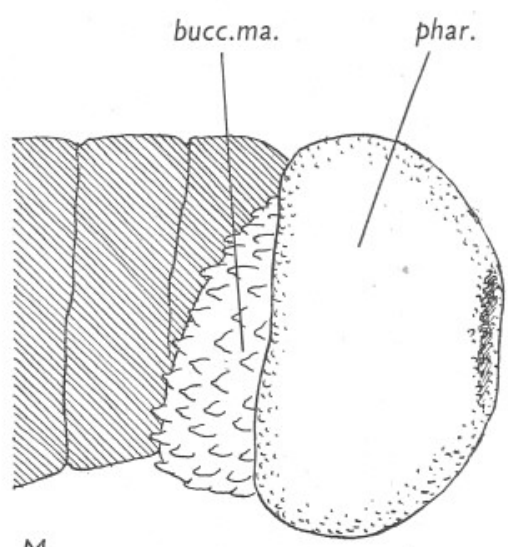

M.

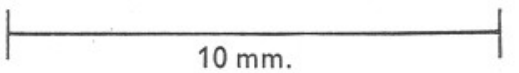

Text-fig. 3. Lateral views of the anterior ends of distended specimens of ecaudata (E.), claparedii (Neapolitan specimen) $(C$.$) and marina (M$.$) . Other lettering as on p. 28$.

The pharynx of claparedii is relatively more extensive than that of ecaudata, and is blown out, at the moment of full extrusion, into a rounded, bubble-like form, which overlaps and conceals the buccal mass. The drawing of Textfig. $3 C$. was made from an artificially distended specimen, but the form of the pharynx resembles that normally seen in the living worm. The expanded pharynx is characterized by a 'waist-line' which corresponds to the attachment of the retractor sheath muscles on its inner surface. The pharyngeal papillae are more spherical than those of ecaudata. The buccal papillae are stout conical teeth, with their apices directed towards the mouth (Text- 
fig. 4 C.). ${ }^{1}$ There is a broad transition zone between buccal mass and pharynx, as in ecaudata (Pl. I, fig. 2).

The proboscis of marina resembles that of claparedii in its pharnyx which assumes a rounded form at full extrusion, and in its conical buccal papillae directed towards the mouth (Pl. I, fig. 3; Pl. II, fig. 2; Pl. IV, fig. 2). Its pharynx differs from that of claparedii in lacking the 'waist-line' and also in being slightly less extensive, so that it overlaps the buccal mass less completely at the moment of full extrusion. On the other hand, the buccal
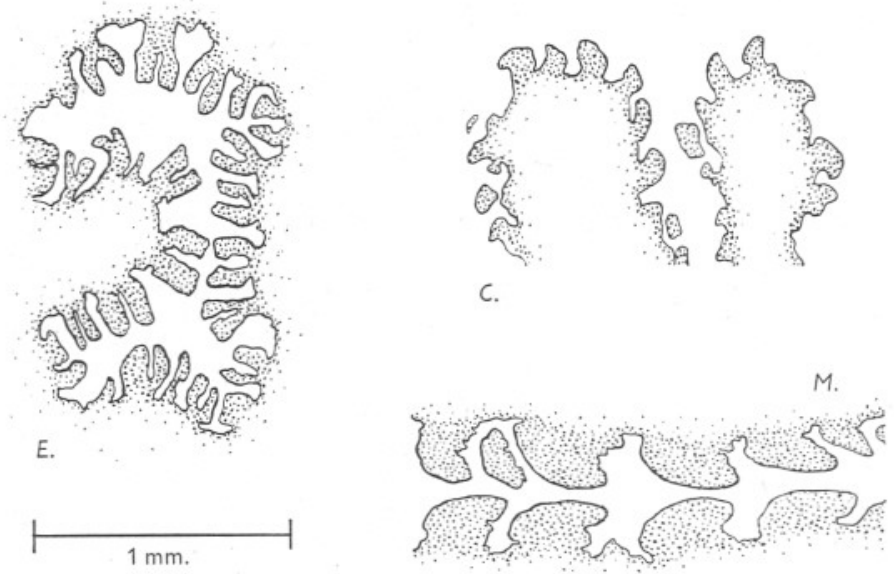

Text-fig. 4. Camera lucida outlines of microtome sections, to show the form of the buccal papillae. E., ecaudata: transverse section through withdrawn buccal mass. C., claparedii (Neapolitan specimen): horizontal section through partly extruded buccal mass. M., marina: sagittal section through withdrawn buccal mass, the oral end to the right.

papillae of marina are larger and more powerful-looking than those of claparedii. I have suggested elsewhere that the buccal mass of marina is used as a rasp in burrowing (Wells, I948). The boundary between buccal mass and pharynx is relatively abrupt in marina; the transition zone exists, but is much narrower than in the other species.

\section{The Buccal Peritoneum}

As already noted, the proboscis papillae are hollowed out by the great development of their interstitial spaces. The relations between these spaces and the main body cavities are of evident functional interest. In the part of the gut which traverses the paraoesophageal cavity, the interstitial spaces open freely into that cavity; this is to be expected if it is itself an enormous inter-

1 The buccal teeth are more rounded in my Neapolitan specimens than in my Canadian ones. This may be due to the fact that the Neapolitan specimens are much smaller; but Ashworth (I9I2) has enumerated several other differences between Neapolitan and Pacific members of this species. The statements in my text about the form of the normally extruded proboscis in claparedii are based on worms watched at Naples in I949. I have not seen living Canadian specimens. 
stitial cleft. The relations of the spaces in the buccal papillae to the head coelome vary from species to species, as follows.
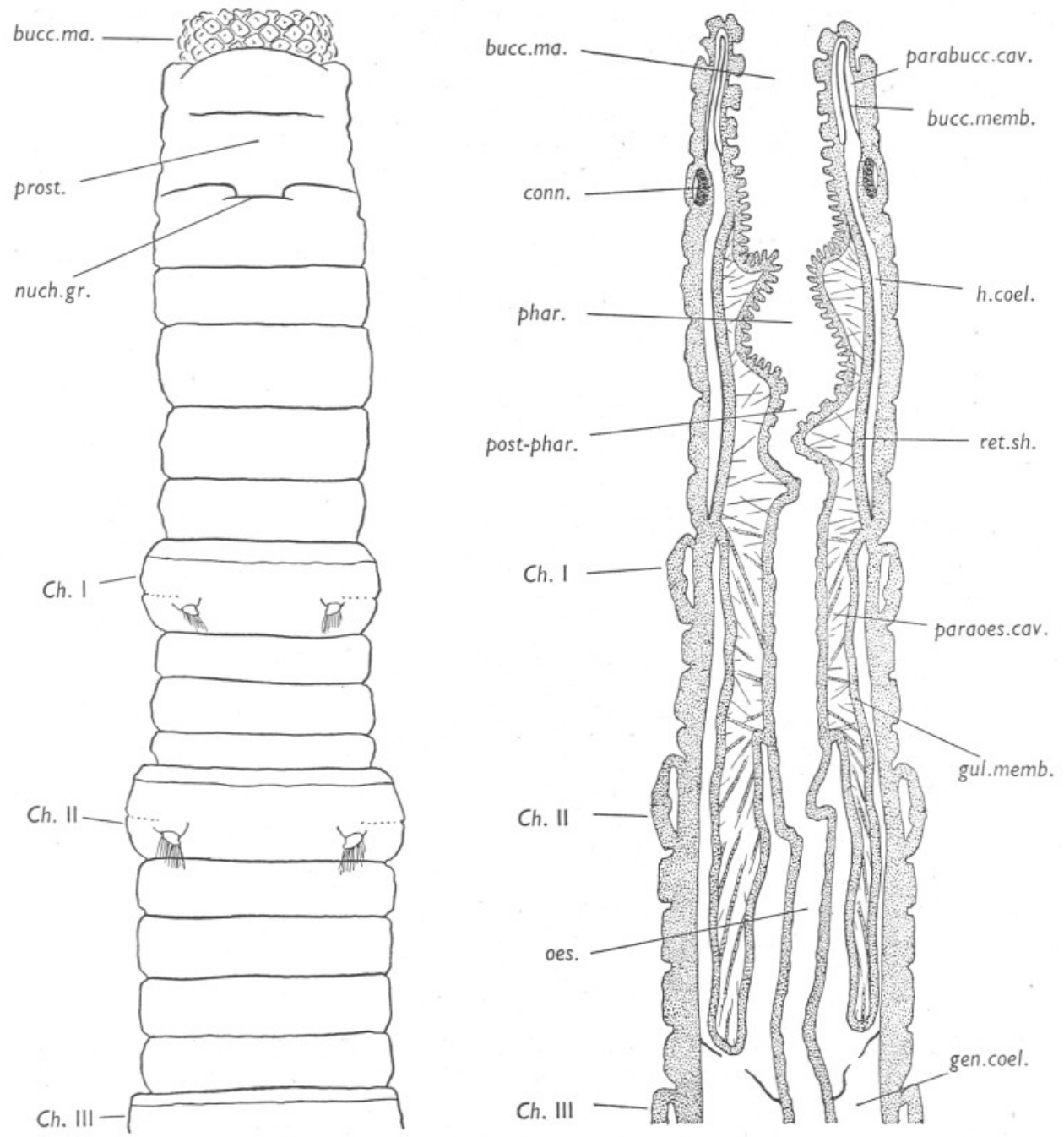

$5 \mathrm{~mm}$.

Text-fig. 5. Horizontal section through the anterior end of ecaudata, and outline of the worm in dorsal aspect. Lettering as on p. 28. (In Text-figs. 5-10, the section was drawn first, from microtome sections or dissections of relaxed specimens, and the surface drawing was then fitted to the same outline.)

The buccal region of ecaudata is characterized by the presence of a stout membrane, the buccal membrane (Text-figs. 5, 6; Pl. IV, fig. 3; bucc.memb.). 
The membrane consists of two very thin epithelial layers with dense connective tissue between them, and separates the head coelome from a smaller cavity, the parabuccal cavity (parabucc.cav.). There is apparently no peritoneal lining between the parabuccal cavity and the tissues of the buccal mass, whose interstitial spaces open freely into the parabuccal cavity. The simplest explanation of these facts is to suppose that the buccal membrane represents the peritoneal lining of the head coelome which has separated away from the
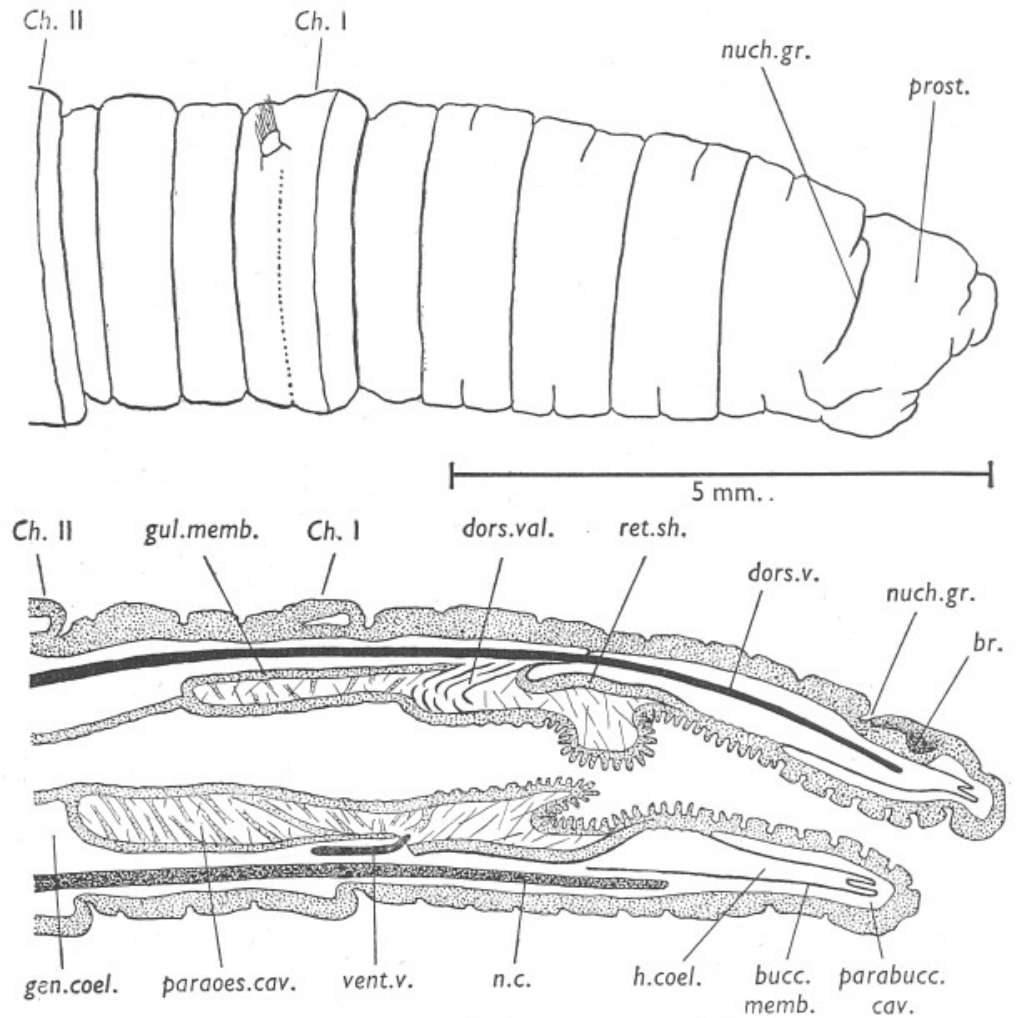

Text-fig. 6. Median sagittal section through the anterior end of ecaudata, and outline of the worm in lateral aspect. Lettering as on p. 28.

other tissues of the buccal mass-a modification which would obviously facilitate the movements of the papillae and of the buccal mass as a whole. On this interpretation, the parabuccal cavity is not coelomic, but an extension of the interstitial spaces. The epithelial layer on that face of the buccal membrane which abuts on the head coelome is the true coelomic epithelium and the other is comparable to the endothelial linings of blood vessels and other non-coelomic cavities.

The buccal membrane meets the gut at the junction of buccal mass and pharynx, and the body wall along the line of the brain and connective nerves. 
Mid-ventrally, it extends backwards for a short distance over the ventral nerve cord and then ends abruptly, in such a way as to leave a narrow passage through which the parabuccal cavity communicates with the head coelome (Text-fig. 6).

There is no buccal membrane in claparedii or marina, and the state of affairs in these species can be derived from that in ecaudata by supposing that it has simply disappeared, throwing head coelome and parabuccal cavity together to form a single space. There is no barrier at all between the interstitial spaces of the buccal papillae and the head coelome (Pl. IV, fig. 4). The disappearance of the buccal peritoneum presumably increases the mobility of the papillae in these two species, since they can be inflated or deflated by varying the pressure in the head coelome.

\section{The Gular Membrane}

This structure varies very greatly from species to species, in general form and in the strength of its musculature.

In ecaudata, the gular membrane reaches its highest degree of development (Text-figs. 5, 6). It is inserted on the oesophagus between the first and second chaetigerous annuli, but it continues farther backwards in the form of two capacious pouches-the septal pouches, in the terminology of Ashworth (I9I2)-which lie lateral and ventral to the oesophagus and reach nearly or quite as far as the third chaetigerous annulus. Sometimes they even pass beyond this annulus, their tips protruding backwards through the large clefts which exist on each side of the 'second diaphragm'. The musculature of the gular membrane of ecaudata differs from that of the other two species in having two layers, a circular lying behind and outside a radial, and each of these layers taken by itself is more massive than the whole musculature of the membrane in marina or claparedii. There is little doubt that contraction of the gular membrane plays a major part in proboscis extrusion in ecaudata.

The dorsal valve of ecaudata is narrow and its terminal perforations are not very large, but the muscle strands in its wall are numerous and well developed. On the ventral side, a pair of stout columns of muscle detach themselves from the lateral walls of the ventral foramen, just beside the point of penetration of the ventral vessel into the paraoesophageal cavity, and cross the cavity to reach the ventral side of the oesophagus, a little way behind the post-pharynx; these are the ventral accessory retractors, and are considerably more massive than those of the other species.

The gular membrane of claparedii shows the most striking contrast to that of ecaudata (Text-figs. 7,8). It is extremely delicate and transparent, and generally thrown into loose folds. Its musculature consists of a very thin layer of radial fibres. The structure as a whole is evidently too delicate to 
be of any importance in proboscis activity; it seems, indeed, to be a vestigial organ. There are no septal pouches.

Along the mid-dorsal line, the gular membrane of claparedii adheres to the gut wall (contrast Text-figs. 6 and 8). The dorsal valve is widely perforated. These two features together suggest that body fluid driven forwards from the hinder segments could enter the paraoesophageal cavity more readily in claparedii than in ecaudata.
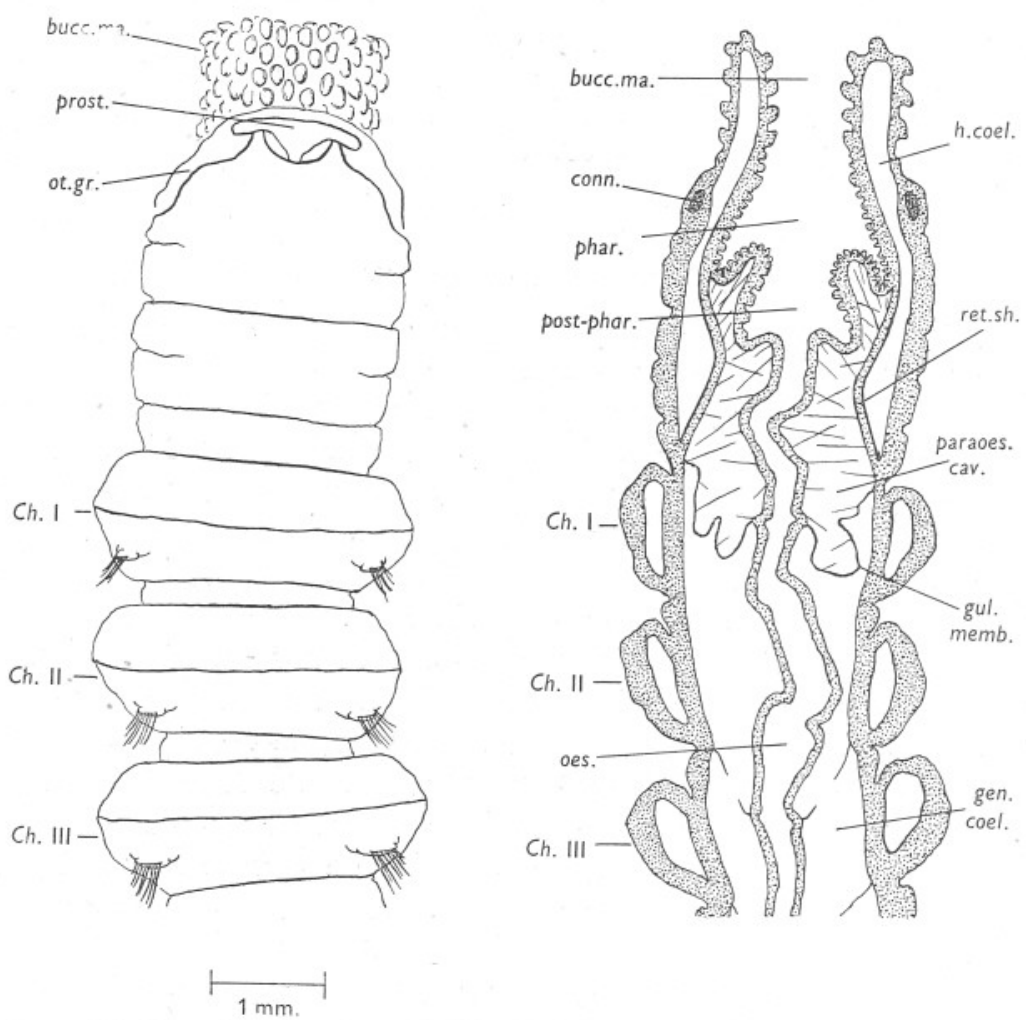

Text-fig. 7. Horizontal section through the anterior end of claparedii (Neapolitan specimen) and outline of the worm in dorsal aspect. Lettering as on p. 28.

The gular membrane of marina is intermediate in its degree of development between those of the other two species. It has the general form of a rather flat cone with the apex directed backwards (in the relaxed worm), and it continues posteriorly into a pair of small septal pouches below the oesophagus (Text-figs. 9, I0). At the point where it meets the oesophagus, the circular muscle layer of the latter forms a conspicuous sphincter. The musculature of the membrane is radial only, but considerably more powerful than that of claparedii. 
The gular membrane of marina is bound closely to the oesophagus by radial strands in the mid-dorsal line. The dorsal valve is more widely perforated than in ecaudata. Forwardly moving fluid in the general coelome could easily enter the paraoesophageal cavity through the dorsal valve.
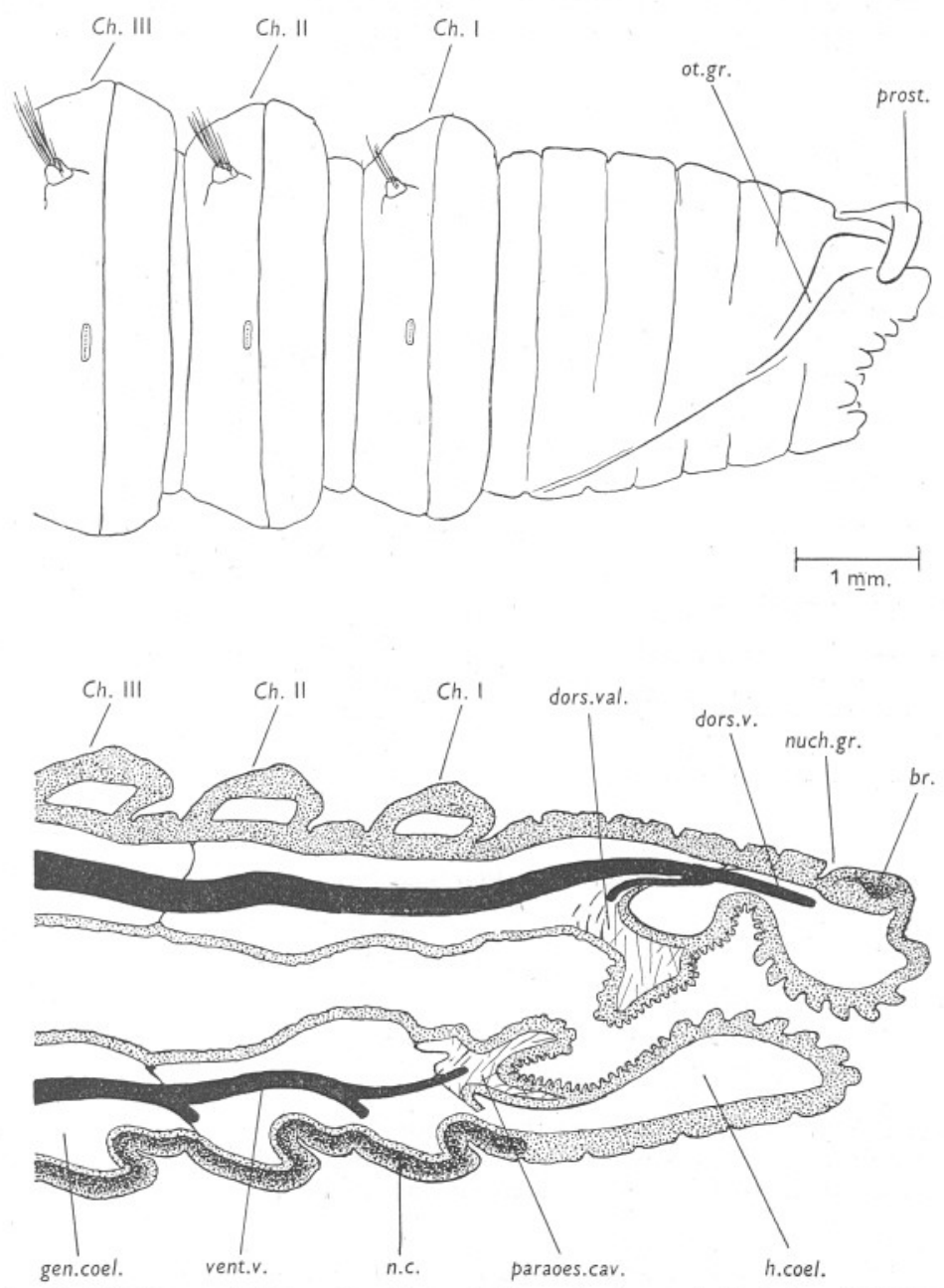

Text-fig. 8. Median sagittal section through the anterior end of claparedii (Neapolitan specimen) and outline of the worm in lateral aspect. Lettering as on p. 28.

There is also a second entry point on the ventral side in marina. As the ventral vessel runs forwards to its point of entry into the paraoesophageal cavity, it is arched over by the floor of the latter (Text-fig. Io). The arch has, in transverse section, roughly the form of a $V$ with the apex upwards. The lateral walls of the $\mathrm{V}$ contain numerous muscle strands running to the mid- 
ventral line of the oesophagus, and their membranous part, though continuous below, is freely perforated between the strands near the apex of the $\mathrm{V}$. The arch may be termed the ventral valve (Pl. III, vent.val.). Fluid can easily flow through the perforations from the general coelome into the paraoesophageal cavity, but a high pressure in the latter would tend to press together the imperforate ventral parts of the side walls, and this would obstruct a reverse flow.
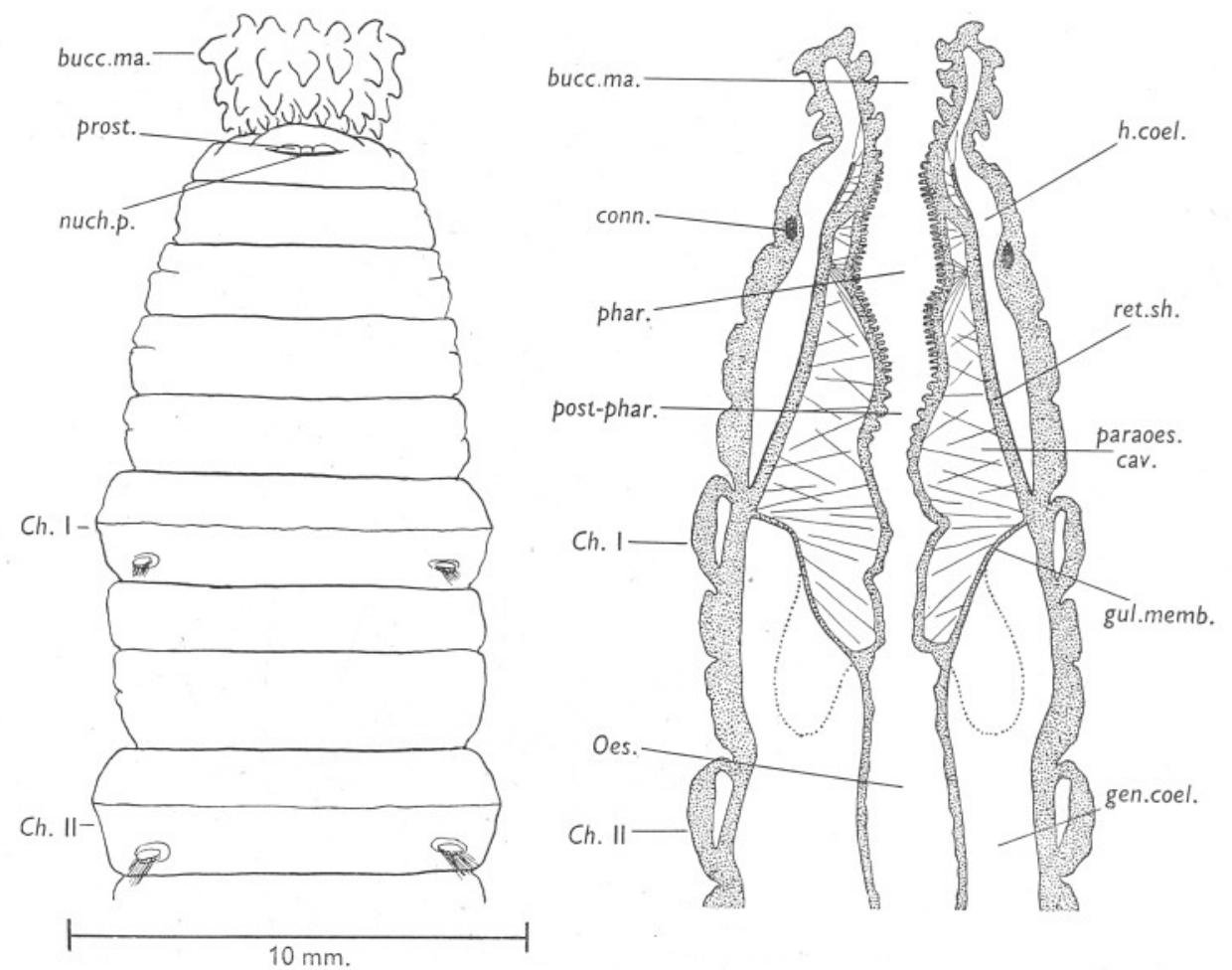

Text-fig. 9. Horizontal section through the anterior end of marina, and outline of the worm in dorsal aspect. The dotted lines give the position of the septal pouches, which lie ventral to the plane of the section. Lettering as on p. 28 .

The Insertion of the Gular Membrane and Retractor Sheath on the Body Wall

The general form of the line of insertion of these two sheets on the body wall is always the same (Text-fig. 2), but its position varies slightly from species to species. In the mid-dorsal line it is farthest forward in claparedii and farthest back in ecaudata (Text-figs. 6, 8 and ro). Ventrally, immediately beside the ventral foramen, the sheets meet the body wall at the anterior boundary of the first chaetigerous annulus in ecaudata, and slightly in front of it in claparedii. In marina the gular membrane meets the ventral body wall 
just behind the anterior margin of the first chaetigerous annulus, while the retractor sheath runs back to the hinder half of the annulus next behind the first chaetigerous annulus.
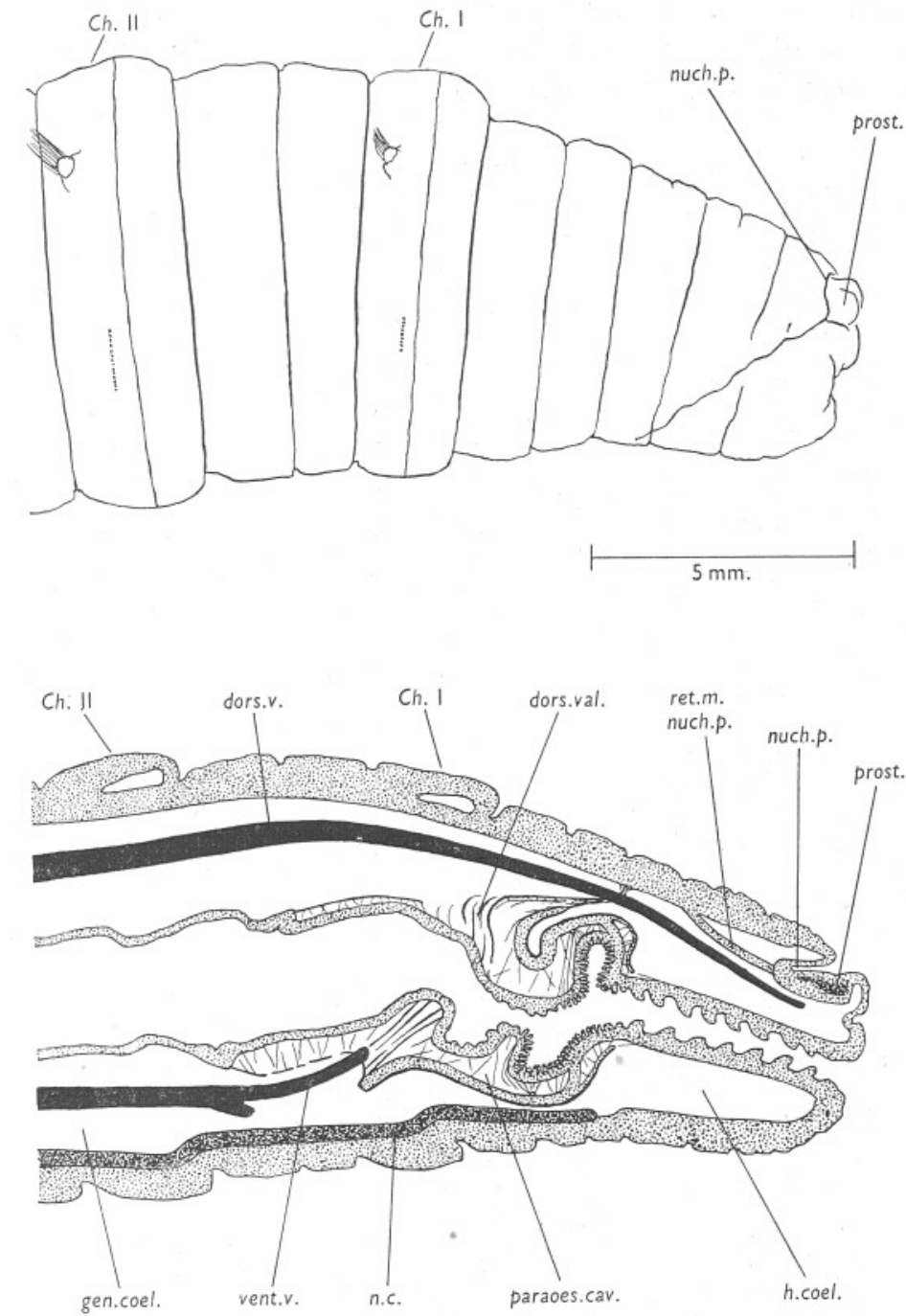

Text-fig. Io. Median sagittal section through the anterior end of marina, and outline of the worm in lateral aspect. Lettering as on p. 28.

The extent to which the head coelome and general coelome can communicate between the body wall and the decussation line of the two sheets is also variable. There is always a ventral foramen, and in ecaudata this is the only communication. In claparedii there are also two large foramina on each side, 
at the levels of the notopodium and neuropodium. In marina there are numerous fine openings round the whole periphery, as can be clearly seen in a well distended specimen. The extent to which these various openings allow fluid to flow between the cavities must be greatly decreased, in any species, if the muscle columns of the two sheets contract in such a way as to pull their decussation against the body wall.
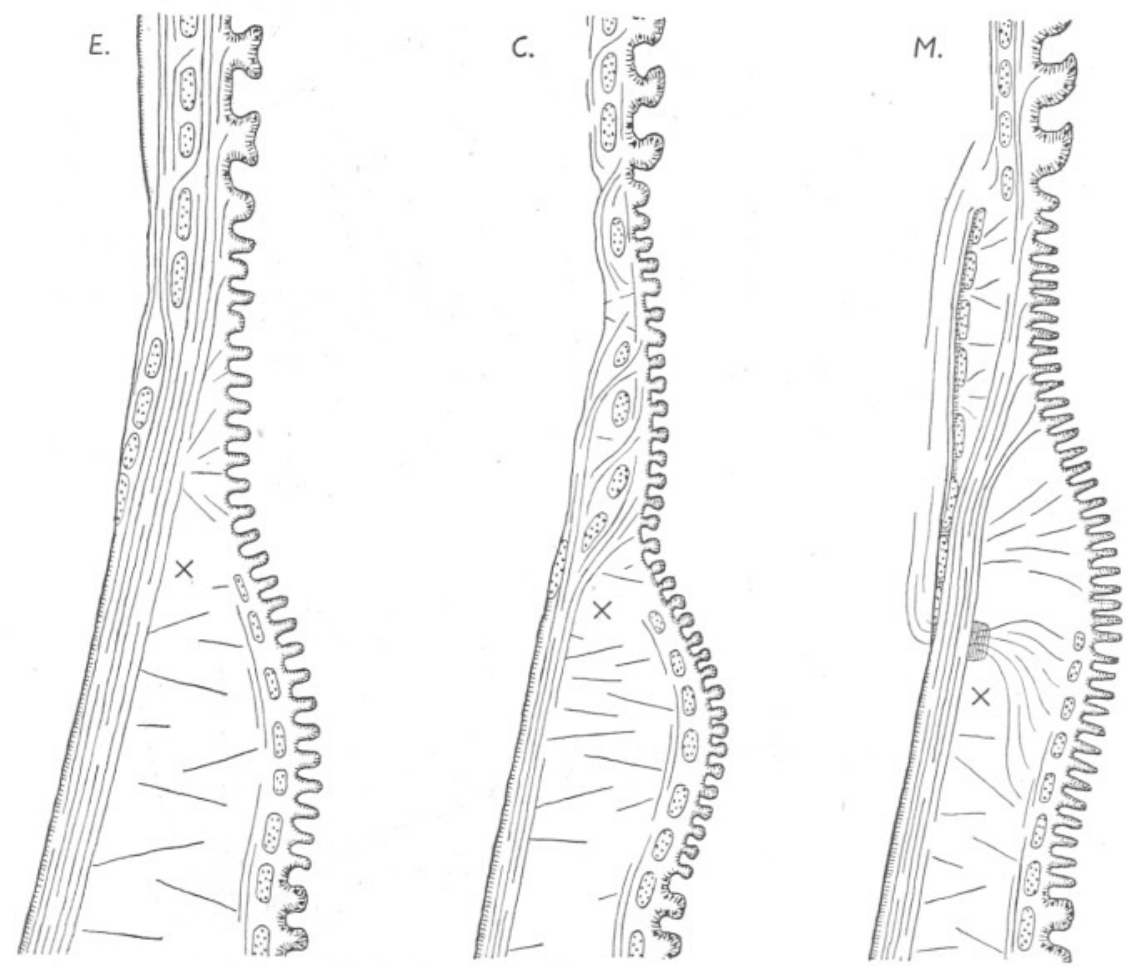

Text-fig. II. Diagrams of longitudinal sections through the junction of retractor sheath and pharynx in ecaudata $(E$.$) , claparedii (C$.$) and marina (M$.$) . Proboscis withdrawn. The$ point of junction is marked $X$. Compare Text-fig. I, p. 3 .

\section{The Union of Retractor Sheath and Pharynx}

The essential features of this important region are drawn diagrammatically in Text-fig. I I for ecaudata (E.), claparedii (C.) and marina (M.). The following points are common to all three drawings. The aboral end of the buccal mass is shown above, its interstitial spaces being separated from the head coelome by the buccal membrane in ecaudata but not in the other species; then follow the pharynx and the oral end of the post-pharynx below. At the lower end of the drawing, the retractor sheath is seen approaching the gut; it consists of coelomic epithelium on the left, connective tissue (cross-shaded) and muscle. The oral end of the paraoesophageal cavity lies between retractor sheath and 
gut. At the point $X$, in each drawing, circular muscle appears on the outside of the retractor sheath. This may be regarded as the true point of arrival of the sheath on the gut wall, from whose circular layer the fibres in question are presumably derived.

In ecaudata the retractor sheath musculature is separated from the gut lining for some distance beyond $X$ by a forward continuation of the paraoesophageal cavity, crossed by numerous radial strands, which extends nearly to the buccal mass. The tissues of the junction of pharynx and buccal mass are compactly put together, and there is little or no possibility of a forward
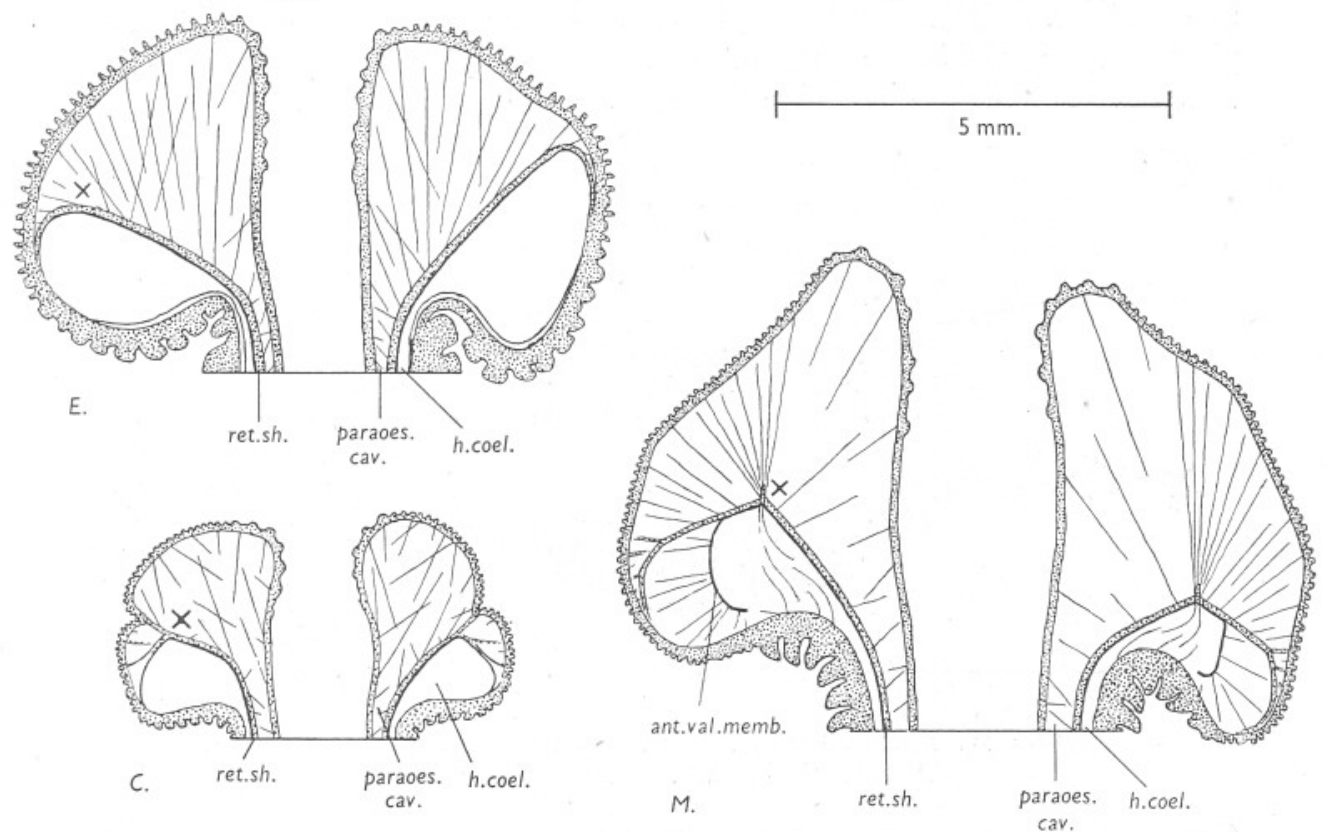

Text-fig. 12. Sections through the extruded proboscis of ecaudata (E.), claparedii (C.) and marina (M.). The position of $X$ is the same as in Text-fig. II. Lettering as on p. 28 .

flow of fluid out of the oral end of the paraoesophageal cavity. The positions assumed by the various components in the extruded proboscis are shown in Text-fig. I2 $E$.

In claparedii the bulk of the retractor sheath musculature crosses to the gut lining immediately oral to $X$ (Text-fig. II $C$.). This is the cause of the 'waist-line' seen in the distended pharynx (Text-figs. ${ }_{3} C$., $\mathrm{I} 2 C$.). The muscle columns constitute a nearly, but not quite, complete partition at this level. On its oral side the tissues of the pharynx are very loose, with extensive interstitial spaces; they are cut off from the head coelome by a delicate but imperforate membrane, presumably peritoneal, which is bound to the gut lining by radial strands, and extends forwards as far as the junction of 
pharynx and buccal mass. Here the tissues are tightly bound together, so there is little or no possibility of a forward escape of fluid from the paraoesophageal cavity.

It is in marina that the most remarkable specializations of this region are found. The breakdown of the buccal peritoneum extends backwards as far as $X$, and the wall of the oral half of the pharynx is greatly modified to form a structure which will be termed the anterior valve (Text-fig. I3). The most characteristic feature of the valve is the anterior valve membrane (ant.val.memb.): this is a continuous membrane encircling the gut and ending anteriorly in a sharp but rather irregular boundary at the level where the pharynx meets the buccal mass. It consists of the following layers: (i) a very thin layer of longitudinal muscle, on the side towards the head coelome;

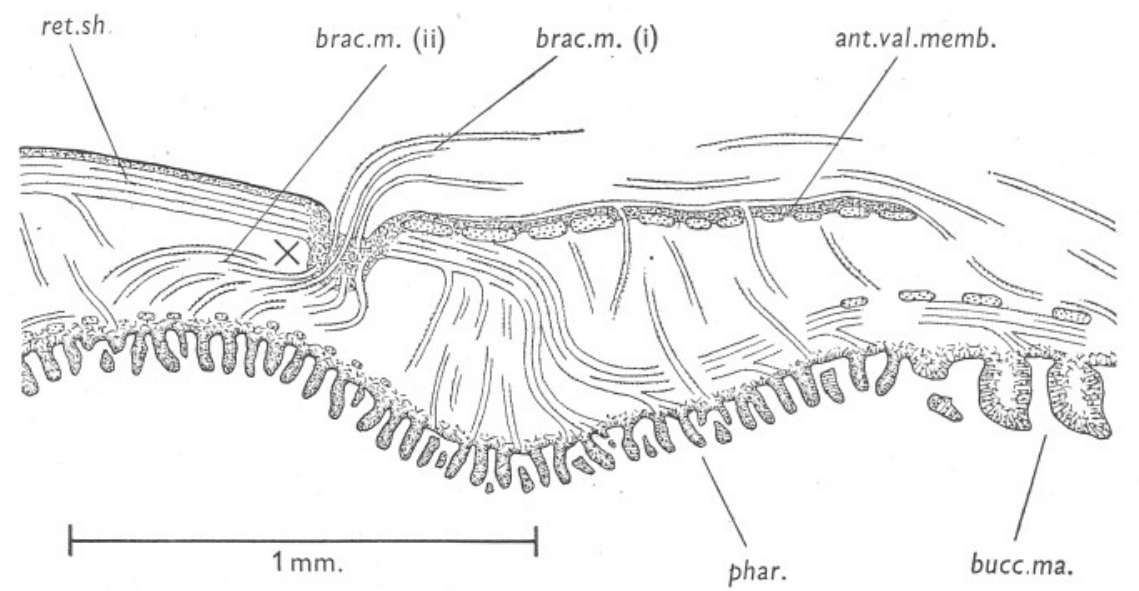

Text-fig. I3. Longitudinal section through the anterior valve of marina. Proboscis withdrawn. Lettering as on p. 28.

(ii) connective tissue; (iii) circular muscle, on the side towards the gut lining. The anterior valve membrane is evidently a part of the gut wall which has split away from the rest. Beneath it there lies a clear space crossed by radial strands; then come the remaining layers of the gut wall (more of the circular muscle, then superficial longitudinal muscle, connective tissue and epithelium). The retractor sheath muscles cross this space (to become the superficial longitudinal layer) as a series of discrete, parallel columns. Fluid can easily flow forwards from the oral end of the paraoesophageal cavity, passing between these columns and under the anterior valve membrane, to reach the head coelome. The valve membrane presumably blocks any reverse flow, at least when the proboscis is withdrawn (Pl. IV, fig. 5).

The muscles of the main (deep) longitudinal layer of the buccal mass run backwards towards the valve as a series of roughly parallel strands. Some of them enter the longitudinal layer of the valve membrane at its free margin 
(often accompanied by strands of connective tissue) and doubtless serve to hold it in position. Others run outside the membrane-i.e. over its coelomic face-and converge, like pencils of rays in an optical diagram, to focus on certain points which are evenly spaced round the periphery of the valve at its level of junction with the retractor sheath; these strands will be termed the oral bracer muscles (Text-figs. I2-I4, brac.m. (i)). At the points on which these strands are focused, the retractor sheath muscles are separated by dense plugs of connective tissue, which are generally pulled rather inwards towards the gut lining. One of the plugs is shown in section in Text-fig. 13. A second series of muscle strands, more numerous than the first, radiates from each

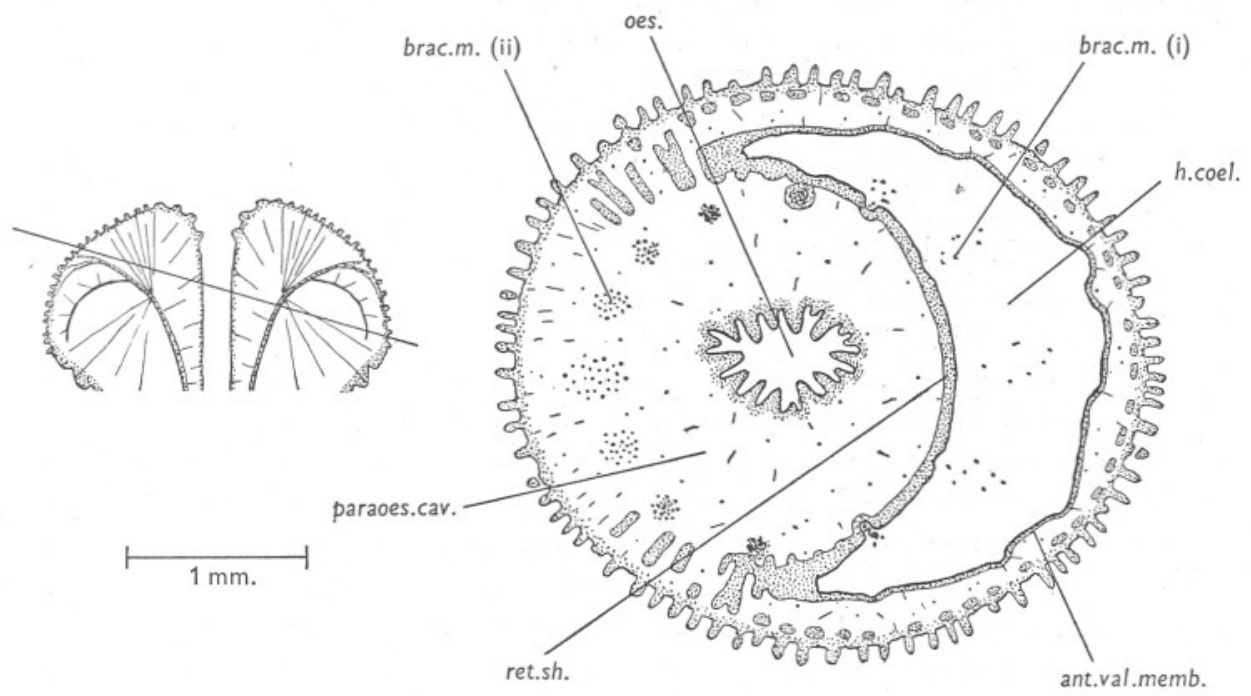

Text-fig. I4. Slightly oblique transverse section through the extruded pharynx of marina, to show the relations of the bracer muscles. Lettering as on p. 28 .

plug to the wall of the aboral half of the pharynx; these will be termed the aboral bracer muscles (brac.m. (ii)). Some of the aboral bracer muscles are direct continuations of the oral ones, but others arise in the plug. The main function of these remarkable muscle strands is probably the holding of the parts in position when the proboscis is extruded (Text-figs. I2, M.; I4).

The configuration of the anterior valve in the distended proboscis is shown in Text-fig. I2, M. and Pl. III. There are wide gaps between the parallel retractor muscle columns as they cross from the base of the anterior valve membrane to the gut lining, and also between the margin of the valve membrane and the buccal mass. No obstacle is presented to a flow of fluid from paraoesophageal cavity to head coelome-and possibly none to a reverse flow in the fully distended proboscis. 


\section{Functional Evolution In the Proboscis Apparatus}

The structural differences between the species are great. The following discussion attempts to explain them in terms of function.

We may assume (i) that the retractor sheath is relaxed at the moment of extrusion, and (ii) that the proboscis is driven out, largely at least, by a forward flow of body fluid. Such a flow could be produced in two ways. The gular membrane could contract, pressing on the fluid in the paraoesophageal cavity-and the body wall of the hinder segments could contract, pressing on the fluid in the general coelome. Contraction of the gular membrane would cause a forward flow in the paraoesophageal cavity, while that of the body wall would have several effects. Thus the coelomic fluid could displace the gular membrane forwards, or enter the paraoesophageal cavity through the dorsal valve (and the ventral valve, in marina), or enter the head coelome through the ventral foramen and such other openings as exist between the decussation line and the body wall. We may note in passing that the structure of the 'second and third diaphragms' is such that they would not seriously obstruct a flow of fluid along the body.

The anatomy of ecaudata strongly suggests that in this species the gular membrane is the main agent in extrusion. Its capacity is great and its musculature is strong. Its contraction would cause a forward movement of the point of union of retractor sheath and pharynx, for the tissues at this point are compactly put together and would block the passage of fluid. The proboscis would therefore be pushed towards the mouth. The body wall could reinforce this action by raising the pressure in the general coelome. A swift and forcible injection of fluid from the general coelome into the paraoesophageal cavity through the dorsal valve seems unlikely to occur, because the extrusion of the proboscis is a reversible process, and there is no means by which the injected fluid could rapidly escape again in ecaudata. Such assistance as the hinder body wall may give is more probably by the application of pressure to the outside of the gular membrane. The function of the dorsal valve may be analogous to that of a trickle charger-to allow the entry of fluid into the paraoesophageal cavity as a replacement for any which has leaked away through the surrounding membranes during normal proboscis activity.

Other factors may play a part in extrusion. For example, contraction of the longitudinal muscles of the body wall of the head would tend to roll the buccal mass forwards and outwards; owing to the incompressibility of the fluid in the head coelome, if there were no simultaneous backward flow through the ventral foramen. It nevertheless seems, from the anatomical relationships, that a forward movement of fluid produced by contraction of the gular membrane musculature is of major importance in ecaudata.

The other two species differ from ecaudata in the following important respects: (i) they distend the proboscis into a fuller, more spherical form; 
(ii) their buccal papillae are teeth, not suckers; (iii) their gular membranes are less extensive and less powerful; (iv) the only communication between the general coelome and head coelome in ecaudata is through the ventral foramen, but the other two species have additional communicating channels (through the dorsal, ventral and anterior valves in marina; through the large openings between decussation line and body wall at the levels of the notopodia and neuropodia in claparedii); (v) they have lost the buccal peritoneum. The third of these differences suggests that the main responsibility for propulsion has shifted from the gular membrane to the body wall; this conclusion seems certain for claparedii and probable for marina. The fourth suggests that the point at which the raised pressure is brought to bear has also shifted. In ecaudata we supposed a forward movement of fluid in the paraoesophageal cavity, blocked by and therefore displacing the union of retractor sheath and pharynx. In marina the development of the anterior valve completely alters the picture; it seems likely that the forwardly moving body fluid would flow through the valve and press on the advancing tip of the buccal mass. In claparedii a rise in the pressure could cause a forward displacement of the delicate gular membrane or a flow through the openings between decussation line and body wall; it could therefore be brought to bear both on the pharynx and on the buccal mass. The fifth difference allows the body fluid to press unhindered into the central cavities of the buccal teeth.

These considerations suggest a co-ordinated evolutionary picture. The supersession of the gular membrane by the body wall means that the proboscis machine is now driven by a motor of much greater power and capacity. The shift in the point at which the fluid pressure operates means that the buccal mass can be used more effectively as a rasp.

The above remarks are, however, speculative. Our knowledge of the movements which the living proboscis performs is still very incomplete, and any theories of its mechanism are therefore insecure. There are differences of habitat between the species: marina and claparedii are chiefly found on sandy and muddy beaches, while ecaudata lives among stones and rocks; but whether there are corresponding differences in the uses to which the proboscis is put remains to be seen. Perhaps, when fuller information about the living worms is available, we shall understand why one species has suckers, and another teeth, on the buccal mass, and this may give us the key to their internal modifications.

\section{SUMMARY}

The anatomy of the structures responsible for proboscis activity is described in detail in Arenicola ecaudata Johnston, A. claparedii Levinsen and A. marina $\mathrm{L}$.

The proboscis apparatus includes the following components: the proboscis itself (i.e. the eversible part of the gut), the first part of the oesophagus, the 
retractor sheath, and the gular membrane ('first septum' or 'first diaphragm ' of previous authors). The retractor sheath and gular membrane are two muscular sheets inserted on the body wall at the same level; the retractor sheath runs to the proboscis and the gular membrane to the oesophagus (Text-figs. I, 2 ; pp. 3, 6). They divide the space between gut and body wall into three distinct cavities, which communicate with each other at certain special points only, as described in the text. These cavities are the head coelome, in front of the retractor sheath, the paraoesophageal cavity between the two sheets, and the general coelome behind the gular membrane. The paraoesophageal cavity is crossed by numerous fine muscle strands, running from the two sheets to the gut.

The suggestion is made that the retractor sheath and gular membrane are both derived from the first septum. A cleft has appeared in the septum, splitting it into the two sheets; the cleft becomes the paraoesophageal cavity.

The papillae of the buccal mass (the oral end of the proboscis) are suckershaped in ecaudata but conical teeth in claparedii and marina. The papillae are hollow, due to the great development of their interstitial spaces. In claparedii and marina, but not in ecaudata, the buccal peritoneum has broken down, so that coelomic fluid in the head coelome can directly enter and distend the papillae.

The gular membrane of ecaudata is very extensive and thrown backwards into a pair of large septal pouches latero-ventral to the oesophagus (Textfigs. 5, 6; pp. I3, I4). Its musculature is powerful and consists of two layers, radial and circular; in the other two species the musculature is radial only. Appearances suggest that the contraction of the gular membrane plays a major part in proboscis extrusion in ecaudata. Such contraction would cause a forward movement of fluid in the paraoesophageal cavity; this would press against and displace the junction of retractor sheath and proboscis and so drive the proboscis forwards.

The gular membrane of claparedii is extremely delicate and lacks septal pouches; it appears to be a vestigial organ (Text-figs. 7,8 ; pp. I6, I7). Proboscis extrusion in this species is probably due to a forward movement of fluid driven by the muscles of the body wall. This fluid could displace the gular membrane and so cause a forward pressure on the junction of retractor sheath and proboscis. It could also flow into the head coelome, through five wide openings between the body wall and the junction of gular membrane and retractor sheath, and so bring pressure to bear on the teeth of the emerging buccal mass.

The gular membrane of marina is intermediate in strength between that of ecaudata and that of claparedii; it has a pair of small septal pouches (Textfigs. 9, I0; pp. I8, I9). The proboscis is probably driven out partly by the gular membrane and partly by the body wall. Fluid can pass from the general coelome into the paraoesophageal cavity through two openings in the median 
plane, the dorsal and ventral valves. The junction of retractor sheath and proboscis is elaborately modified in marina to form the anterior valve, through which fluid can flow from the paraoesophageal cavity into the head coelome (Text-fig. I3, p. 22). These modifications probably mean that the main pressure of the forwardly moving body fluid is brought to bear on the teeth of the advancing buccal mass.

\section{REFERENCES}

Ashworth, J. H., I904. Arenicola. Liverpool Marine Biology Committee Memoirs, Vol. XI. London.

I9I2. Catalogue of the Chaetopoda in the British Museum. A. Polychaeta. Part I. Arenicolidae. London.

Gamble, F. W. \& Ashworth, J. H., I898. The habits and structure of Arenicola marina. Quart. Fourn. Micr. Sci., Vol. 4I, pp. I-42.

I900. The anatomy and classification of the Arenicolidae, with some observations on their post-larval stages. Quart. Fourn. Micr. Sci., Vol. 43, pp. 4I9-570.

Lillie, RALPH S., I905. The structure and development of the nephridia of Arenicola cristata Stimpson. Mitt. Zool. Sta. Neapel, Vol. 17, pp. 34I-405.

WELLS, G. P., I948. Thixotropy and the mechanics of burrowing in the lugworm (Arenicola marina L.). Nature, Vol. 162, pp. 652-3.

- 1950 . The anatomy of the body wall and appendages in Arenicola marina L., Arenicola claparedii Levinsen and Arenicola ecaudata. Johnston. Fourn. Mar. Biol. Assoc., Vol. 29, pp. I-44.

\section{EXPLANATION OF PLATES}

\section{Plate I}

Lateral views of the anterior ends of three artificially distended specimens, to show how the form of the proboscis differs from species to species.

Fig. I. Arenicola ecaudata. The hollow to the left is due to caving-in of part of the pharynx after preservation. The mouth is just beyond the left-hand boundary. The buccal mass and transition zone are fully exposed.

Fig. 2. A. claparedii (Canadian specimen). The buccal mass is concealed by the pharynx, but the transition zone is clearly seen on the right of the latter.

Fig. 3. A. marina. Part of the buccal mass is seen ventrally, in a rather abnormal position due to the distension.

\section{Plate II}

Figs. I, 2. Lateral views of the anterior ends of relaxed specimens of $A$. ecaudata (fig. I) and A. marina (fig. 2). The buccal mass is partly extruded in each. Note the contrast in form of the buccal papillae.

Fig. 3. Dorsal half of a horizontally bisected specimen of A. marina. Proboscis withdrawn. Compare Text-figs. I and 9, pp. 3 and 18.

Fig. 4. Horizontal section through the anterior segments of a $\mathrm{I} \cdot 5 \mathrm{~mm}$. post-larval A. cristata. Lettering as on p. 28.

\section{PLATE III}

Dissection from the right side of a distended specimen of Arenicola marina (same specimen as in Pl. I, fig. 3). An explanatory drawing is placed below the photograph. The dissection has been carried nearly, but not quite, to the median plane. The anterior part of the oesophagus and the tip of the dorsal valve have been removed altogether, to show the 
internal structure of the proboscis; then follows an area over which the right lateral wall of the oesophagus has been removed (cross shading in the drawing). The ventral edge of the left septal pouch is visible in the angle between ventral vessel, ventral mesentery and gular membrane (dark stippling in the drawing). Lettering as below. Compare Text-figs. Io and I2, M., pp. I9 and 21 .

\section{Plate IV}

Figs. I, 2. Longitudinal sections through single buccal papillae of $A$. ecaudata (fig. I) and marina (fig. 2). Both worms are relaxed, with the proboscis withdrawn. The buccal papilla of ecaudata is sucker-shaped, with the top depressed; its internal musculature is clearly shown. That of marina is tooth-shaped (oral end to the left ); a small blood vessel is entering the base of the papilla and there is another in the tip of the 'tooth'.

Figs. 3, 4. Transverse sections including the ventral body wall (below) and the ventral wall of the buccal mass (above) in ecaudata (fig. 3) and marina (fig. 4). The two sections are as nearly as possible from the same position, i.e. just in front of the bifurcation of the ventral nerve cord. The sucker-shape of the buccal papillae of ecaudata is again obvious. The two folds of the buccal membrane of ecaudata are seen as thick, rather wavy lines crossing the middle of fig. 3 ; the narrow space between them is the head coelome (compare Text-figs. 5 and 6, pp. 13, I4). In marina, there is no barrier between the head coelome and the interstitial cavities of the buccal papillae.

Fig. 5. Longitudinal section through the anterior valve of marina. Relaxed specimen; proboscis withdrawn; oral end to the right. The section corresponds to Text-fig. I3, p. 22, except that it does not happen to pass through a bracer muscle perforation. The pale grey object on the upper margin of the photograph, about half-way along, is a longitudinally-running blood vessel; a group of bracer muscle strands can be seen just below it.

Pl. II, fig. 3, was taken by the late Mr F. J. Pittock, and is reproduced from the fournal of Experimental Biology, Vol. I4, I937, by kind permission of the Company of Biologists Ltd.

The other photographs were taken for this work by the following: Pl. I, by Miss J. Hubbard; Pl. II, figs. I and 2, and Pl. III, by Mr J. Armstrong; Pl. II, fig. 4, and Pl. IV, by Mr W. Brackenbury.

\section{List of Abbreviations used in the Text-Figures and Plates}

ant.val.memb.

br.

brac.m. (i)

brac.m. (ii)

bucc.ma.

bucc.memb.

Ch.

circ.m.

conn.

D.

D.vest.

dors.mes.

dors.v.

dors.val.

ep. E c.t.

gen.coel. gul.memb. h.coel. long.m. metast.m.

n.c. brain

oral bracer muscles

aboral bracer muscles

buccal mass

buccal membrane

chaetigerous annulus

circular muscle

connective nerve

diaphragm

diaphragm which becomes vestigial

dorsal mesentery

dorsal vessel

dorsal valve

epithelium and connective tissue

general coelome

gular membrane

head coelome

longitudinal muscle nuch.gr. nuch.p.

oes.

ot.gr.

parabucc.cav. parabuccal cavity

paraoes.cav. paraoesophageal cavity

phar.

post-phar.

prost.

ret.m.nuch.p.

ret.sh.

sup.long.m.

vent.for.

vent.mes.

vent.v.

vent.val. metastomial muscle

nerve cord

nuchal groove

nuchal pouch

oesophagus

otic groove

pharynx

post-pharynx

prostomium

retractor muscle of the nuchal pouch

retractor sheath

superficial longitudinal

muscle

ventral foramen

ventral mesentery

ventral vessel

ventral valve 

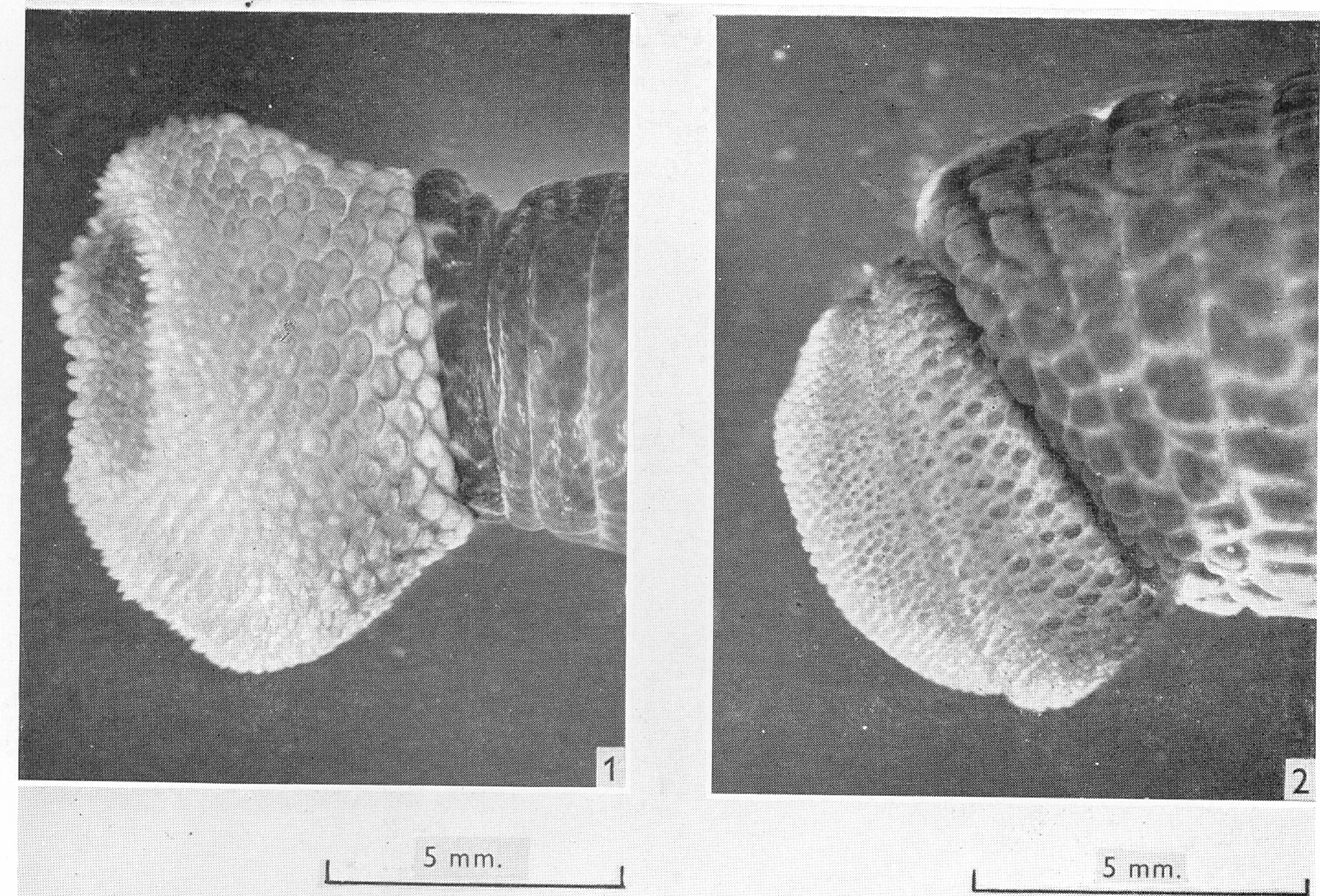

$5 \mathrm{~mm}$.

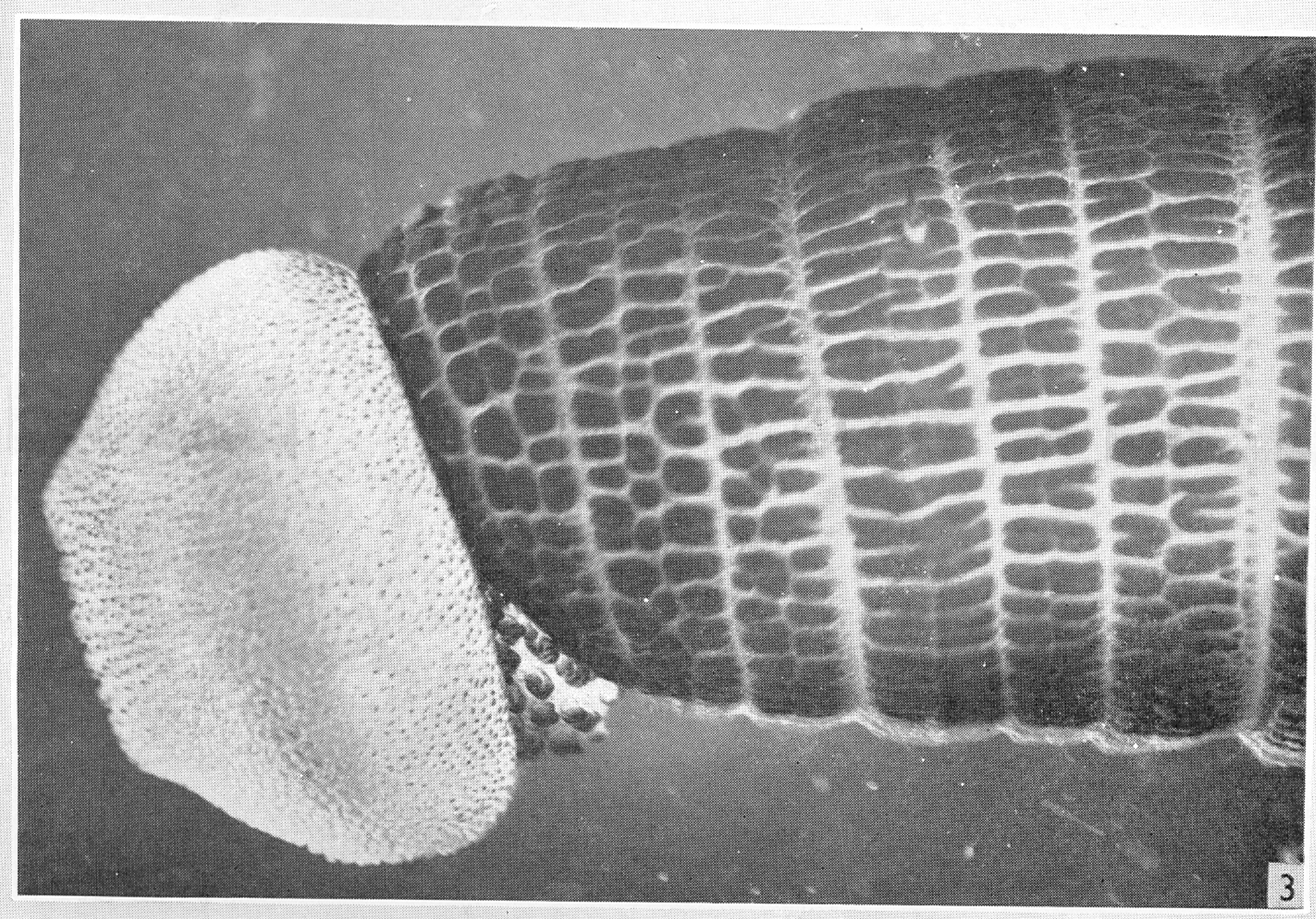




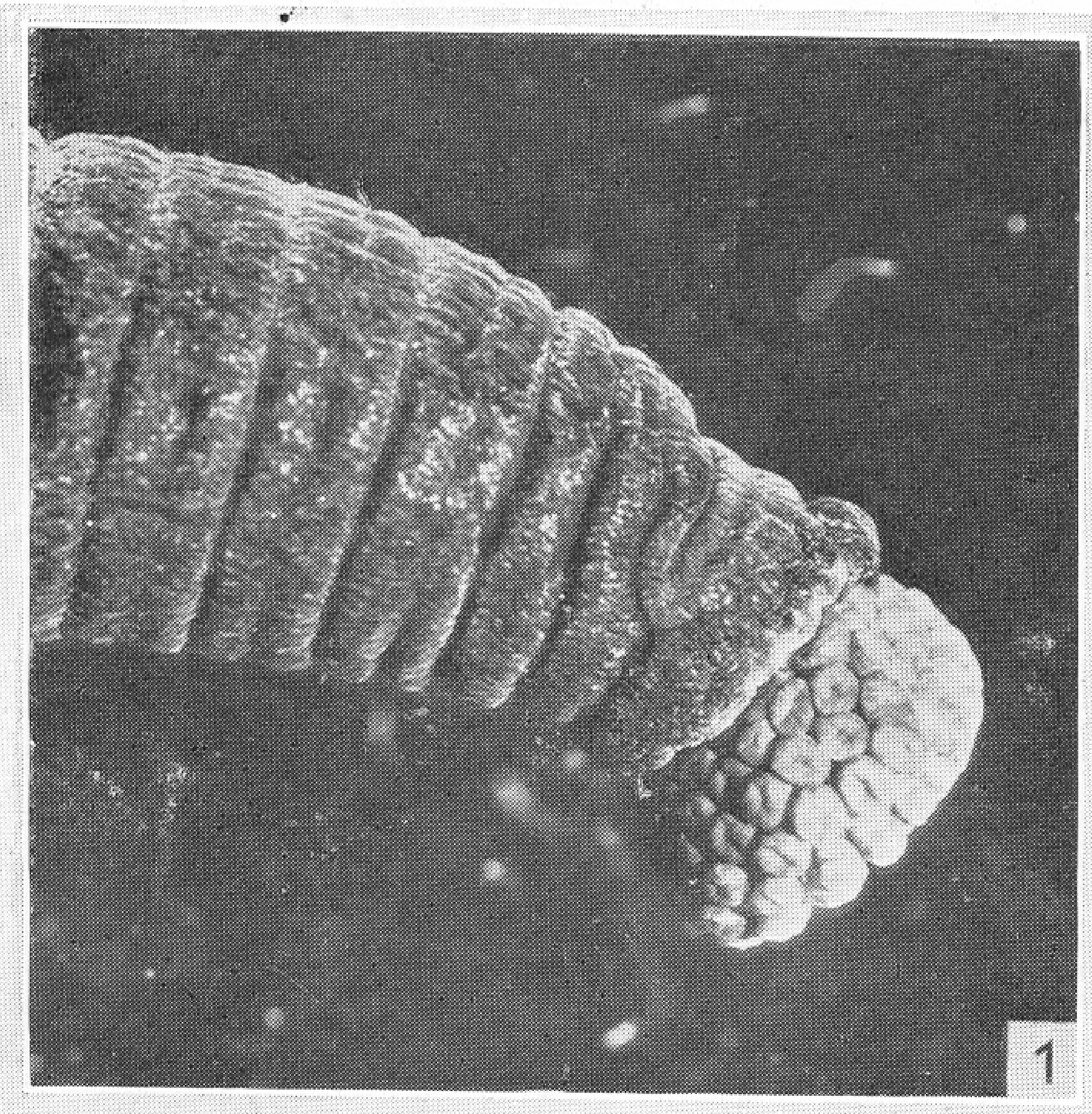

$5 \mathrm{~mm}$.

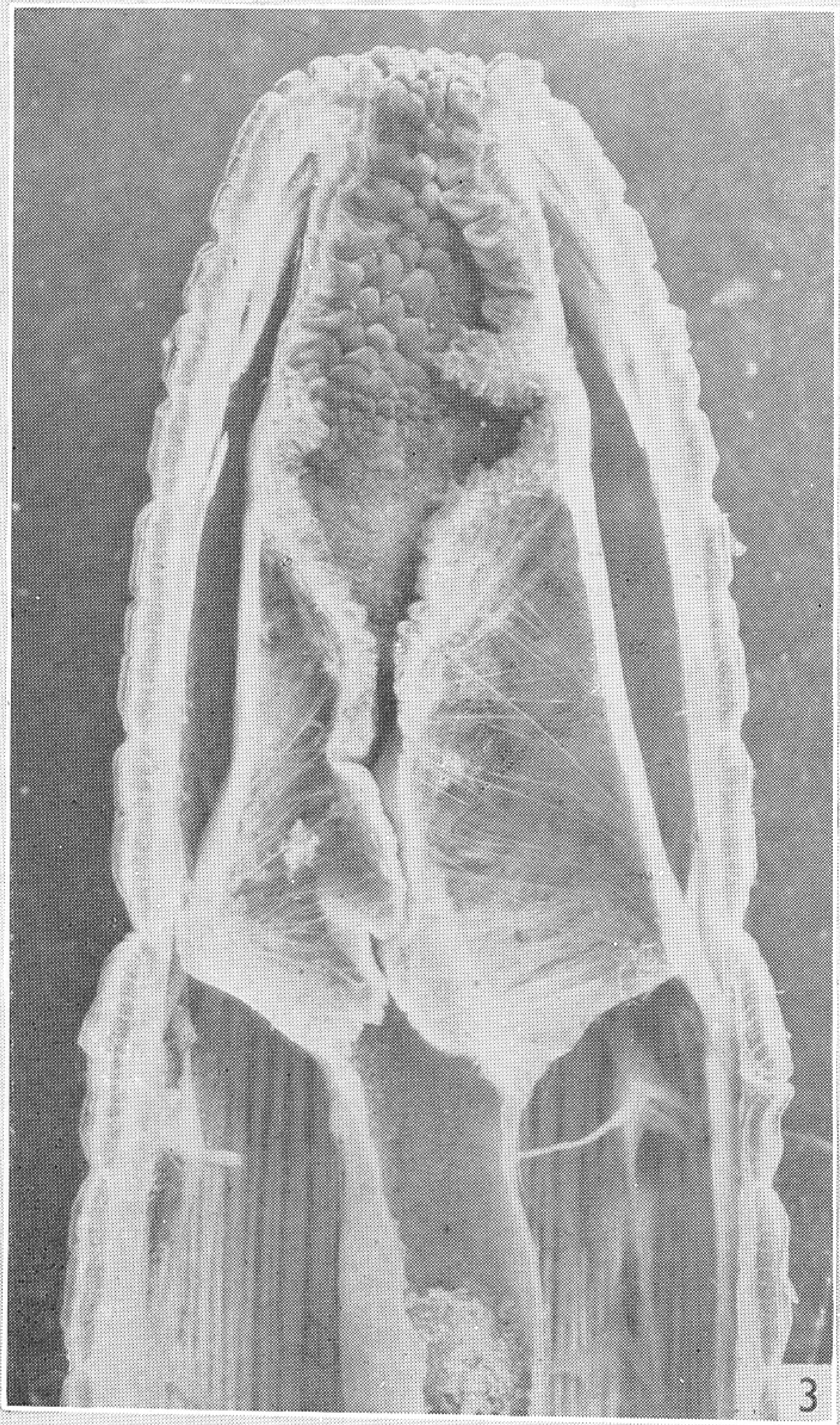

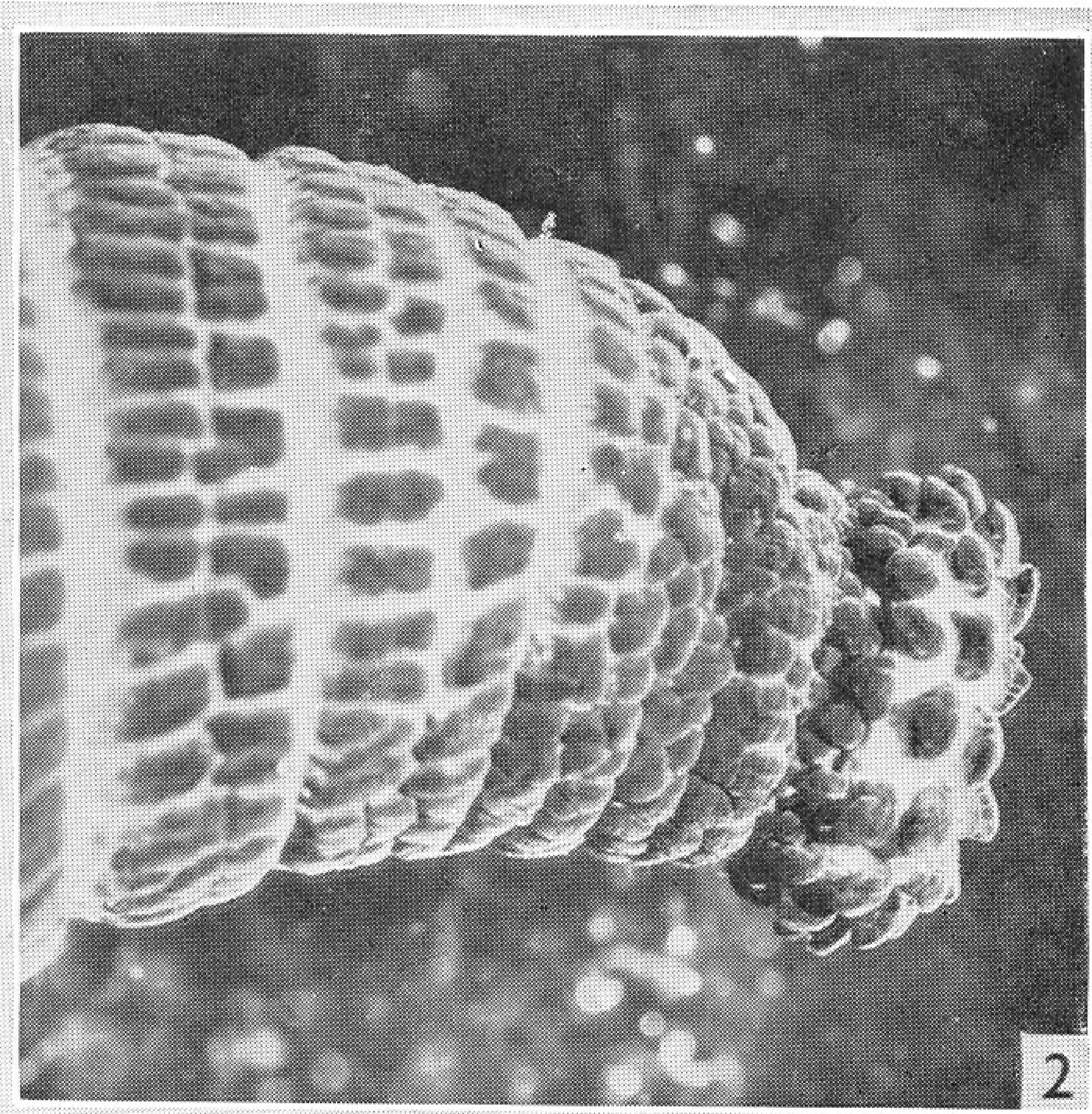

$5 \mathrm{~mm}$.

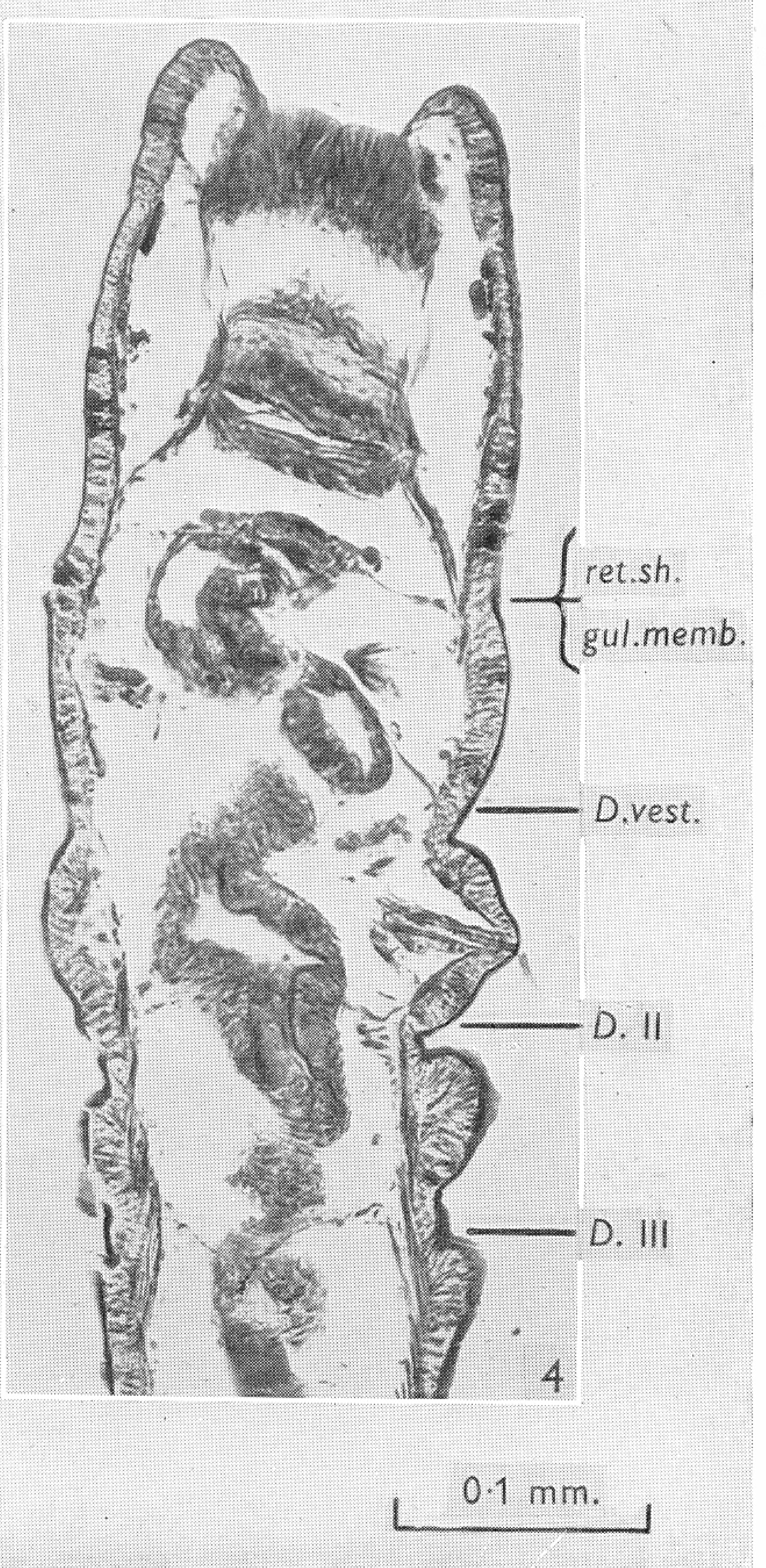



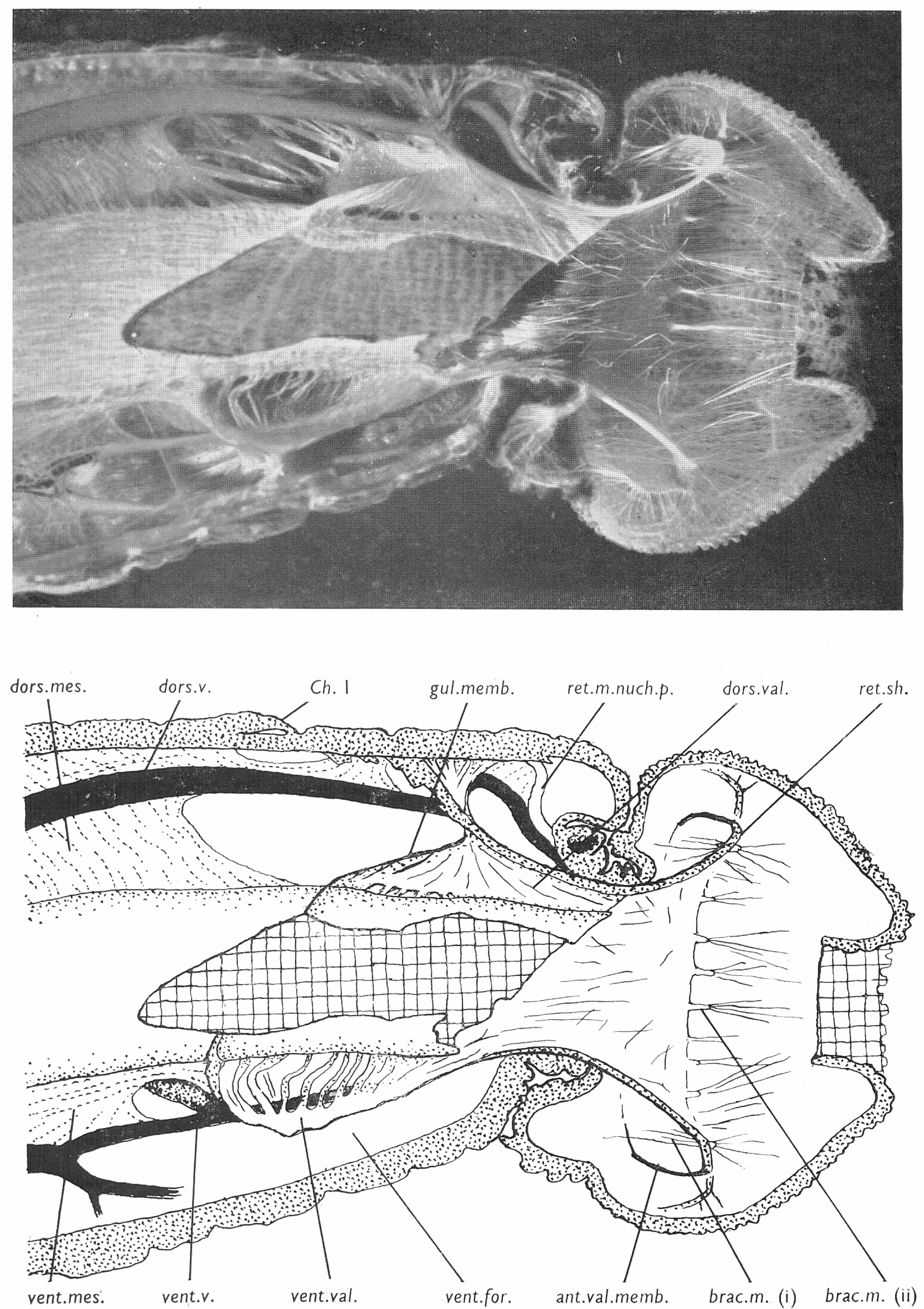

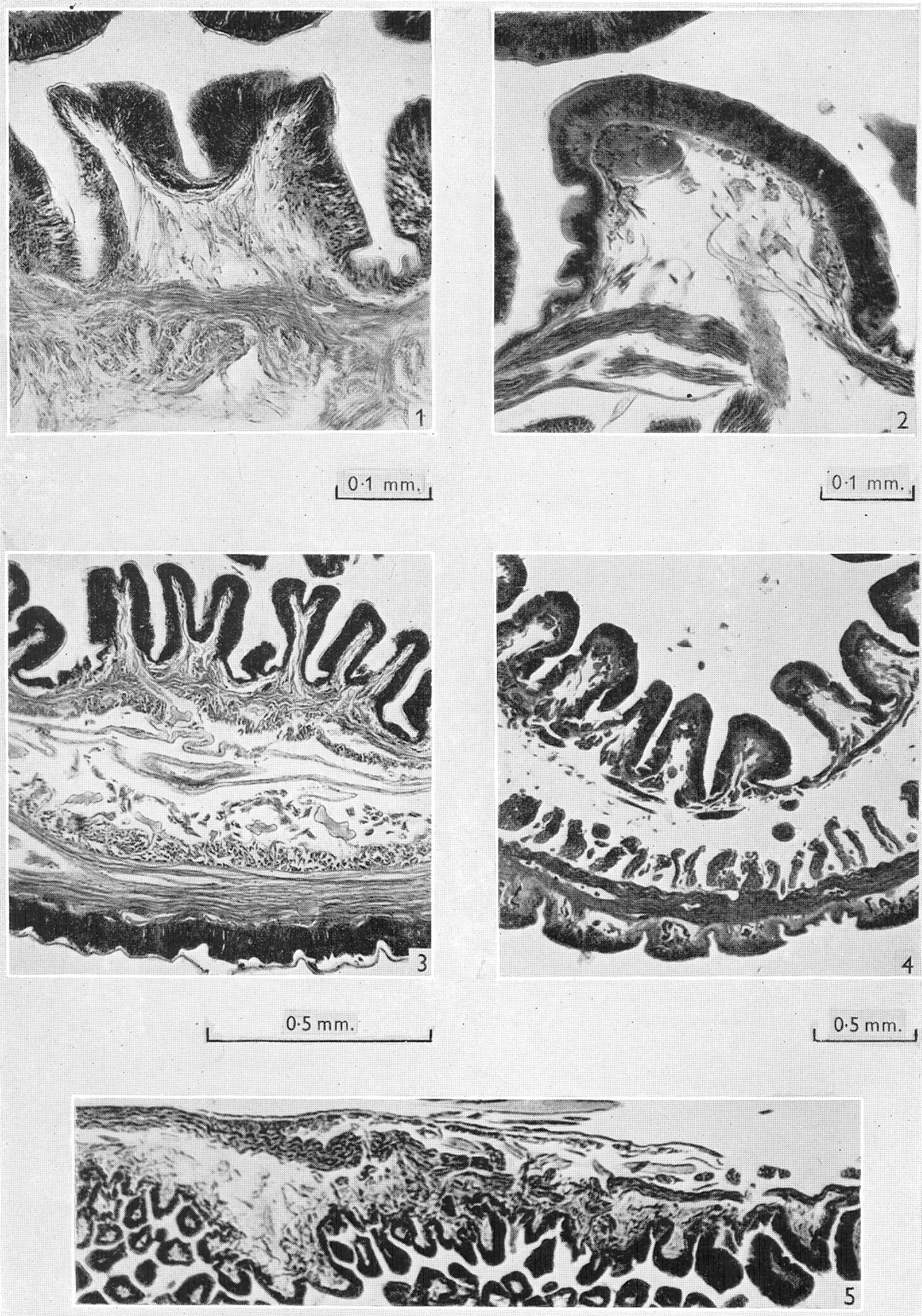